\title{
Inflammasome, T Lymphocytes and Innate- Adaptive Immunity Crosstalk: Role in Cardiovascular Disease and Therapeutic Perspectives
}

\author{
Daniela Pedicino ${ }^{1, *}$ Ada Francesca Giglio ${ }^{1, *}$ Aureliano Ruggio ${ }^{1}$ Gianluca Massaro ${ }^{1}$ Alessia D’Aiello ${ }^{1}$ \\ Francesco Trotta ${ }^{1}$ Claudia Lucci $^{1}$ Francesca Graziani ${ }^{1}$ Luigi Marzio Biasucci ${ }^{1} \quad$ Filippo Crea ${ }^{1, * *}$ \\ Giovanna Liuzzo ${ }^{1, * *}$
}

${ }^{1}$ Department of Cardiovascular and Thoracic Sciences,
IRCCS-Fondazione Policlinico Universitario A. Gemelli, Catholic
University of the Sacred Heart, Rome, Italy

Thromb Haemost 2018;118:1352-1369.

\author{
Address for correspondence Giovanna Liuzzo, MD, PhD, Department of \\ Cardiovascular and Thoracic Sciences, IRCCS-Fondazione Policlinico \\ Universitario A. Gemelli, Largo A. Gemelli, Catholic University of the \\ Sacred Heart, 8-00168 Rome, Italy (e-mail: giovanna.liuzzo@gmail.com).
}

\begin{abstract}
Keywords

- precision medicine

- inflammasome

- innate immunity

- adaptive immunity

- coronary artery disease

- acute coronary syndromes

Over the past few decades, lot of evidences have shown atherosclerosis as a chronic progressive disease with an exquisite inflammatory feature. More recently, the role of innate immune response in the onset and progression of coronary artery disease (CAD) and an adaptive immunity imbalance, mostly involving $T$ cell sub-sets, have been documented. Therefore, like in many other inflammatory and autoimmune disorders, an altered innate-adaptive immunity crosstalk could represent the key of the inflammatory burden leading to atherosclerotic plaque formation and progression and to the breakdown of plaque stability. In this review, we will address the role of inflammasome in innate immunity and in the imbalance of adaptive immunity. We will discuss how this altered immune crosstalk is related to CAD onset and progression. We will also discuss how unravelling the key molecular mechanisms is of paramount importance in the development of therapeutic tools to delay the chronic progression and prevent the acute destabilization of atherosclerotic plaque.
\end{abstract}

\section{Introduction}

The immune system consists of two different, tightly connected arms, which guarantee both immediate and long-term immunity to pathogens. Complement, pattern recognition receptors (PRRs), anti-microbial proteins and phagocytes are the main mediators of innate immune system, acting as the first step in immune responses, then inducing and regulating the second arm of adaptive immunity. B- and T-lymphocytes, the key elements of adaptive

* Daniela Pedicino and Ada Francesca Giglio have contributed equally. ${ }^{* *}$ Filippo Crea and Giovanna Liuzzo have contributed equally.

immunity, are involved in long-term immune response to foreign and, in some cases, self-antigens, so their activation needs to be tightly regulated to avoid chronic inflammatory and autoimmune diseases. The role of innate immune responses in the onset and progression of coronary artery disease (CAD) has been widely documented, together with an adaptive immunity imbalance, mostly involving $T$ cell sub-sets. The aim of this review is to discuss whether and how the inflammasome activation is able to influence adaptive immunity response and $\mathrm{T}$ cell sub-set differentiation, being part of the immune dysregulation leading to atherosclerosis and plaque instability. ${ }^{1-3}$

(c) 2018 Georg Thieme Verlag KG Stuttgart · New York
DOI https://doi.org/

10.1055/s-0038-1666860. ISSN 0340-6245. 


\section{Inflammasome Mediators: PRRs, Caspase-1 and Interleukin-1 $\beta$}

'Inflammasome' is a macro-molecular complex whose activation, after recognition of microbial and/or cell damage signals, results in the cleavage and activation of caspase-1, with subsequent secretion of interleukin (IL)- $1 \beta$ and other pro-inflammatory cytokines. The key mediators and the different types of inflammasome known to date are described in the following paragraphs (see - Tables $\mathbf{1}$ and $\mathbf{2}$ for a classification of human receptors involved in inflammasome activation) ${ }^{4-6}$

\section{PRRs and Inflammasome Forming Proteins}

Over the past 15 years, our understanding of the molecular mechanisms regulating the innate immune system has dramatically changed based on the identification of the PRRs, germline-encoded key receptors able to identify ancestral motifs and signatures of potential harmful agents. ${ }^{7}$ Toll-like receptors (TLRs), expressed on cell surface and endosome's membranes, mostly sense microbial products (pathogen-associated molecular patterns), while nucleotide oligomerization domain-like receptors (NLRs), retinoic acid inducible gene I-like receptors and absent in melanoma 2 (AIM2)-like receptors function as pathogen sensors in intra-cellular compartments. Through these intra-cellular receptors, the innate immune system recognizes also a class of signals in the form of cellular stressors, collectively termed 'danger signals' or danger-associated molecular patterns (DAMPs). NLRs and AIM2 take part to the assembling of the inflammasome, ${ }^{1}$ and NLRs are also involved in a particular form of inflammation-induced programmed cell death, named pyroptosis. ${ }^{8,9}$ Triggers and pathways determining cell fate upon commitment of NLRs, inflammatory state or cell death, are still incompletely understood. Nevertheless, the specific linkage between inflammasome activation and pyroptosis has been recently better clarified by the identification of gasdermin $\mathrm{D}$, a protein able to form membrane pores leading to the inflammatory cell death, upon caspase- 1 and caspase- 11 mediated cleavage ${ }^{10}$ ( - Fig. 1).

To date, four cytoplasmic PRRs able to form an inflammasome complex have been described: NLRP1, NLRP3, NLRC4 and AIM2. ${ }^{1,4-6,11}$

NLRP1 (also called NALP1) was the first member of the NLR family to be identified. ${ }^{11}$ It is expressed in different cell sub-types (such as monocytes, dendritic cells, granulocytes and lymphocytes) and it is activated by the anthrax lethal toxin produced by $B$. anthracis. ${ }^{12}$

NLRP3 (also called NALP3, CIAS1 or cryopyrin) has been the most extensively studied inflammasome activator, due to the wide array of its microbial and non-microbial ligands. Bacteria (including Staphylococcus aureus, Escherichia coli and Chlamydia trachomatis), viral and fungal pathogens (such as Influenza A virus, Candida albicans and Saccharomyces cerevisiae) and parasites (such as Schistosoma mansoni) are known activators. Non-microbial triggers of NLRP3 include crystals (monosodium urate, cholesterol crystals, calcium pyrophosphate dehydrate, silica, alum), proteins such as $\beta$-amyloid, haptens and ultraviolet irradiation. ${ }^{13}$
NLRC4 (also known as IPAF, CARD12 or CLAN) is mainly expressed in lymphoid tissues and gastrointestinal tract and it is activated by a more limited range of triggers. Gram-negatives bacteria (such as Salmonella, Legionella, Shigella or Pseudomonas) seem to be mostly involved in its activation. ${ }^{14-16}$

AIM2 is the only PRR that does not belong to the NLR family receptors. It probably initiates inflammasome formation after the binding to double-stranded deoxyribonucleic acid (DNA), taking part in the cytosolic recognition of several pathogens. ${ }^{17}$

\section{Caspase-1}

Caspases are a family of cysteine proteases that cleave their substrates after an aspartic acid residue. While the majority of caspases are well known for their role in the apoptotic process, a few so-called 'inflammatory caspases' (caspase- $1,-4,-5$ and -12 in humans) are important for the proteolytic activation and secretion of inflammatory mediators. ${ }^{1,11,13}$ Caspase- 1 is recruited after NLRs activation, and it is the final common pathway of inflammasome activation, involved in the proteolityc cleavage of many inflammatory mediators, such as IL- $1 \beta$ and IL-18, and apoptotic caspases. ${ }^{18,19}$ In resting cells, caspase1 is inactive; once recruited by an inflammasome platform, caspases can proteolytically activate each other; the cleavage of gasdermin D downstream of caspase-1 might provide a mechanistic link to pyroptosis. ${ }^{10}$ Furthermore, even if inflammasome/caspase- 1 pathway is classically associated to proinflammatory and detrimental functions, recent studies have also revealed anti-inflammatory and protective functions of caspase-1, mediating tissue healing and cell survival. ${ }^{20}$

\section{Interleukin-1 $\beta$}

IL- $1 \beta$ is the prototypic pro-inflammatory cytokine, implicated in acute and chronic inflammatory disorders and produced in response to inflammatory stimuli, such as TLR activation and other pro-inflammatory cytokines. IL- $1 \beta$ induces a wide range of genes, including cyclooxygenase-2, inducible nitric oxide synthase, other cytokines such as IL-6 and tumour necrosis factor (TNF), chemokines, matrix metalloproteinases (MMP) and adhesion molecules. Acting as a bone marrow stimulant, it increases myeloid progenitor cells and induces neutrophilia. ${ }^{21,22}$ IL-1 $\beta$ activation requires proteolytic cleavage of its inactive precursor pro-IL-1 $\beta$ performed by caspase-1, activated within the inflammasomes (-Fig. 2).

\section{Inflammasome Activation: The NLRP3 Model}

NLRP3 inflammasome requires double-step activation. Under resting condition, NLRP3 protein is in a self-inhibiting state (probably mediated by leucine-rich repeat domain); substrates as pro-IL-1 $\beta$, pro-IL-18, pro-caspase-1 and NLRP3 itself are not highly expressed. Any known nuclear factorkappa B (NF-kB) activating stimulus can be an inflammasome-priming signal. ${ }^{23,24}$ These stimuli could be both microbial, through the involvement of PRRs such as TLRs, and nonmicrobial, including IL- $1 \beta$ itself. Upon priming stimulation, substrates like NLRP3 and pro-IL1 $\beta$ are transcribed but not activated. Only after a specific NLRP3 trigger (such as $\mathrm{K}^{+}$ 
Table 1 Human NLR classification

\begin{tabular}{|c|c|c|c|}
\hline Family & Member $^{a}$ & Other names and aliases & Tissue expression \\
\hline NLRA & CIITA & NLRA; MHC2TA; C2TA & Thymic epithelium, B cells, dendritic cells, monocytes \\
\hline NLRB & NAIP & NLRB1; BIRC1; CLR5.1 & Macrophages \\
\hline \multirow[t]{5}{*}{ NLRC } & NOD1 & NLRC1; CARD4; CLR7.1 & $\begin{array}{l}\text { Heart, spleen, placenta, lung and epithelium, ovary, } \\
\text { pancreas, placenta, skeletal muscle, testis }\end{array}$ \\
\hline & NOD2 & $\begin{array}{l}\text { NLRC2; CARD15; CD; } \\
\text { BLAU; IBD1; PSORAS1; } \\
\text { CLR16.3 }\end{array}$ & $\begin{array}{l}\text { Monocytes, dendritic cells, granulocytes, intestinal } \\
\text { epithelial cells, Paneth cells }\end{array}$ \\
\hline & NLRC3 & NOD3; CLR16.2 & $\begin{array}{l}\text { Highest expression in purified T cells, B cells and NK cells, } \\
\text { but also in thymus, uterus, kidney }\end{array}$ \\
\hline & NLRC4 & $\begin{array}{l}\text { CARD12; CLAN; CLR2.1; } \\
\text { IPAF }\end{array}$ & $\begin{array}{l}\text { Bone marrow, macrophage, colon, kidney, liver, lung, } \\
\text { spleen, placenta, intestine, heart (weak) and testis (weak) }\end{array}$ \\
\hline & NLRC5 & NOD27; CLR16.1 & $\begin{array}{l}\text { Macrophage, lymphocytes, immune-related tissues } \\
\text { (bone marrow, lymph node, spleen and in PBLs), lung, } \\
\text { small intestine, colon, uterus }\end{array}$ \\
\hline \multirow[t]{14}{*}{ NLRP } & NLRP1 & $\begin{array}{l}\text { NALP1; DEFCAP; NAC; } \\
\text { CARD7; CLR17.1 }\end{array}$ & $\begin{array}{l}\text { Heart, thymus, spleen, peripheral blood leukocytes, } \\
\text { monocytes, dendritic cells, B cells and T cells, stomach, } \\
\text { gut, neurons and testis }\end{array}$ \\
\hline & NLRP2 & $\begin{array}{l}\text { NALP2; PYPAF2; NBS1; } \\
\text { PAN1; CLR19.9 }\end{array}$ & Thymus, placenta and lung \\
\hline & NLRP3 & $\begin{array}{l}\text { CIAS1; PYPAF1; Cryo- } \\
\text { pyrin; CLR1.1; NALP3 }\end{array}$ & $\begin{array}{l}\text { Peripheral blood leukocytes, chondrocytes, monocytes, T } \\
\text { cells, dendritic cells, oropharynx, oesophagus, ectocervix }\end{array}$ \\
\hline & NLRP4 & $\begin{array}{l}\text { NALP4; PYPAF4; PAN2; } \\
\text { RNH2; CLR19.5 }\end{array}$ & $\begin{array}{l}\text { Highest in spleen, but also in kidney, lung, liver, placenta, } \\
\text { thymus and pancreas }\end{array}$ \\
\hline & NLRP5 & $\begin{array}{l}\text { NALP5; PYPAF8; MATER; } \\
\text { PAN11; CLR19.8 }\end{array}$ & Oocytes \\
\hline & NLRP6 & $\begin{array}{l}\text { NALP6; PYPAF5; PAN3; } \\
\text { CLR11.4 }\end{array}$ & $\begin{array}{l}\text { Epithelium, granulocytes, monocytes, T cells, B cells, } \\
\text { eosinophils, dendritic cells (weak) }\end{array}$ \\
\hline & NLRP7 & $\begin{array}{l}\text { NALP7; PYPAF3; NOD12; } \\
\text { PAN7; CLR19.4 }\end{array}$ & $\begin{array}{l}\text { Liver, lung, placenta, spleen, thymus, peripheral blood } \\
\text { leukocytes, testis and ovaries }\end{array}$ \\
\hline & NLRP8 & $\begin{array}{l}\text { NALP8; PAN4; NOD16; } \\
\text { CLR19.2 }\end{array}$ & Ovaries, testes and pre-implantation embryos \\
\hline & NLRP9 & $\begin{array}{l}\text { NALP9; NOD6; PAN12; } \\
\text { CLR19.1 }\end{array}$ & Ovaries, testes, oocytes and pre-implantation embryos \\
\hline & NLRP10 & $\begin{array}{l}\text { NALP10; PAN5; NOD8; } \\
\text { PYNOD; CLR11.1 }\end{array}$ & Brain, heart, skeletal muscle, monocytes \\
\hline & NLRP11 & $\begin{array}{l}\text { NALP11; PYPAF6; } \\
\text { NOD17; PAN10; CLR19.6 }\end{array}$ & $\begin{array}{l}\text { Brain, GI tract, female reproductive system, skin, lung, } \\
\text { blood }\end{array}$ \\
\hline & NLRP12 & $\begin{array}{l}\text { NALP12; PYPAF7; Mon- } \\
\text { arch 1; RNO2; PAN6; } \\
\text { CLR19.3 }\end{array}$ & $\begin{array}{l}\text { Granulocytes, dendritic cells, monocytes, leukocytes, } \\
\text { PBMCs }\end{array}$ \\
\hline & NLRP13 & $\begin{array}{l}\text { NALP13; NOD14; PAN13; } \\
\text { CLR19.7 }\end{array}$ & Female reproductive system \\
\hline & NLRP14 & $\begin{array}{l}\text { NALP14; NOD5; PAN8; } \\
\text { CLR11.2 }\end{array}$ & Testes \\
\hline NLRX & NLRX1 & NOD9; CLR11.3 & Immune cells \\
\hline
\end{tabular}

Abbreviations: GI, gastrointestinal; HGNC, HUGO Gene Nomenclature Committee; NK cells, natural killer cells; NLR, nucleotide-binding oligomerization domain (NOD)-like receptor; PBL, peripheral blood lymphocyte; PBMC, peripheral blood mononuclear cell; Note: To date, more than 20 NLRs have been described, divided in four main sub-classes based on their different N-terminal domain: NLRA (acid transactivation domain), NLRB (baculoviral inhibitory repeat [BIR]-like domain), NLRC (caspase-recruitment domain [CARD]), NLRP (pyrin domain [PYD]). The table shows the different NLRs groups and their expression in the tissues.

aHGNC-approved symbol. 
Table 2 Receptors involved in inflammasome activation

\begin{tabular}{|l|l|l|l|l|}
\hline Receptor & Approved name & Domain organization & $\begin{array}{l}\text { Chromosomal } \\
\text { location }\end{array}$ & $\begin{array}{l}\text { Activation stimuli or mi- } \\
\text { crobial motifs recognized }\end{array}$ \\
\hline NLRP1 & $\begin{array}{l}\text { NLR family, pyrin domain } \\
\text { containing 1 }\end{array}$ & $\begin{array}{l}\text { PYD-NACHT/NBD-LRR- } \\
\text { FIIND-CARD }\end{array}$ & $17 \mathrm{p} 13.2$ & $\begin{array}{l}\text { B. anthracis (Anthrax Lethal } \\
\text { Toxin, in mice), MDP }\end{array}$ \\
\hline NLRP3 & $\begin{array}{l}\text { NLR family, pyrin domain } \\
\text { containing 3 } \\
\text { (also known as NALP3, } \\
\text { CIAS1 or Cryopyrin) }\end{array}$ & PYD-NACHT/NBD-LRR & $1 \mathrm{q} 44$ & $\begin{array}{l}\text { Bacterial mRNA, bacterial } \\
\text { DNA:RNA hybrids, MDP, } \\
\text { DNA and RNA viruses, fungi, } \\
\text { protozoa, ATP, uric acid } \\
\text { crystals, silica, aluminium } \\
\text { hydroxide, asbestos, bee } \\
\text { venom }\end{array}$ \\
\hline NAIP/ & $\begin{array}{l}\text { NLR family, CARD domain } \\
\text { containing 4 } \\
\text { (also known as IPAF, } \\
\text { CARD12 or CLAN) }\end{array}$ & CARD-NACHT/NBD-LRR & $2 \mathrm{p22.3}$ & $\begin{array}{l}\text { Flagellin, bacterial needle } \\
\text { and inner rod proteins from } \\
\text { Gram-pathogens with type } \\
\text { III or type IV secretion sys- } \\
\text { tem (Salmonella, Legionella, } \\
\text { Shigella, Pseudomonas), but } \\
\text { it has been also described a } \\
\text { flagellin-independent } \\
\text { activation }\end{array}$ \\
\hline AIM2 & Absent in melanoma 2 & PYD-HIN 200 & & $\begin{array}{l}\text { Cytosolic dsDNA from virus } \\
\text { and bacteria (such as F. } \\
\text { tularensis, L. monocyto- } \\
\text { genes, } M \text {. tuberculosis, S. } \\
\text { pneumoniae, CMV and vac- } \\
\text { cinia virus) }\end{array}$ \\
\hline
\end{tabular}

Abbreviations: ATP, adenosine triphosphate; CARD, caspase activation and recruitment domain; CMV, cytomegalovirus; dsDNA, double-stranded deoxyribonucleic acid; FIIND, domain with 'function to flnd'; HIN 200, haemopoietic expression, interferon-inducibility, nuclear localization; LRR, leucine-rich repeat; MDP, muramyl dipeptide; mRNA, messenger ribonucleic acid; NACHT/NBD, nucleotide-binding and oligomerization domain; NAD, NBD-associated domain; NLR, nucleotide-binding oligomerization domain (NOD)-like receptor; PYD, pyrin domain.

efflux, $\mathrm{Ca}^{2+}$ signalling, reactive oxygen species (ROS)induced mitochondrial dysfunction and lysosomal destabilization), the inflammasome is assembled and activated, with the subsequent cleavage and release of IL-1 $\beta$ (-Fig. 2). Recently, the site-specific phosphorylation of NLRP3 mediated by c-Jun N-terminal kinase has been described as a key event for the subsequent inflammasome assembly. ${ }^{25}$ Specific kinases, such as double-stranded ribonucleic acid (RNA)-dependent protein kinase and Nek7 seem to be also involved in inflammasome activation. ${ }^{26,27}$ Among the non-crystalline stimuli of NLRP3, recent studies highlight a specific role of disturbed flow and hypoxia. Indeed, hypoxic human macrophages have been demonstrated to produce higher amount of IL-1 $\beta$ than normoxic macrophages ${ }^{28}$ and endothelial cells exposed to pro-atherogenic disturbed flow conditions expressed higher levels of NLRP3, caspase- 1 and IL-1 $\beta .{ }^{29}$ Moreover, specific proteins involved in the regulation of microtubule dynamics orchestrate NLRP3 inflammasome activation, by controlling its transport to optimal activation sites. ${ }^{30}$

\section{Cardiovascular Disease and Inflammation: The Role of Inflammasome and IL-1及}

The inflammatory nature of atherosclerosis is well established but the agents that excite inflammation in the artery wall remain largely unknown. ${ }^{31,32}$ Numerous evidences suggest a pivotal role of IL- $1 \beta$ in CAD, but the relevance of inflammasome activation in each phase of atherosclerosis, from plaque formation to acute coronary syndromes (ACS) and chronic heart failure (HF), needs to be further elucidated. Both in CAD patients presenting with acute myocardial infarction (AMI) and in stable CAD patients, elevated blood levels of soluble and cell-bound members of the TNF superfamily, as well as from the IL-1 family (IL-1B, IL-18) were detected and correlated with the subsequent risk of cardiovascular death or chronic HF. ${ }^{33-38}$

\section{Inflammasome and Plaque Formation}

Recent studies demonstrated that common cardiovascular risk factors such as tobacco smoking and higher body mass index positively correlate with systemic NLRP3 levels. ${ }^{39}$ Atherosclerotic arteries express higher levels of IL-1 $\beta$ and IL-1 receptor 1 (IL-1R1), as compared with normal arteries, while increased IL-1 receptor antagonist (IL-1Ra) levels are associated with reduced coronary atherosclerosis. ${ }^{40}$ The in vitro addition of IL-1 $\beta$ and TNF- $\alpha$ to human macrophages induces increased foam cell formation, with dose-dependent retention of cholesterol and triglycerides. ${ }^{41}$ Cholesterol crystals induce secretion of IL-1 $\beta$ from human monocytes and macrophages, through the activation of NLRP3 inflammasome, while the inhibition of NLRP3 leads to a drastic reduction of IL-1 $\beta$ levels, thus identifying NLRP3 inflammasome as the cholesterol crystal-responsive element in 


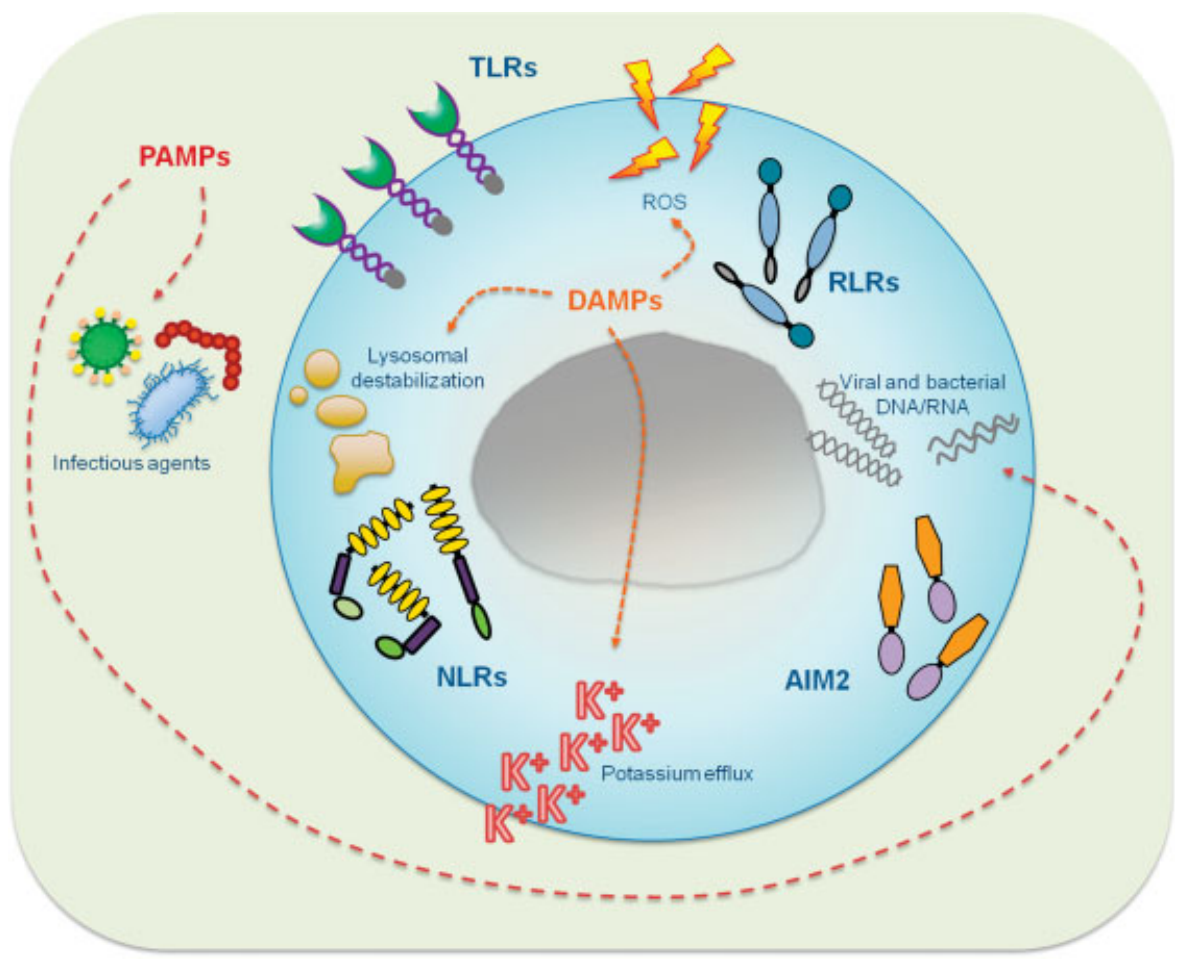

Fig. 1 Pattern recognition receptors (PRRs). Four main classes of PRRs have been described: Toll-like receptors (TLRs), retinoic acid inducible gene-I (RIG-I)-like receptors (RLRs), nucleotide-binding oligomerization domain (NOD)-like receptors (NLRs) and absent in melanoma 2 (AIM2) receptors. Whereas TLRs, expressed on cell surface and endosome's membranes, are mostly addressed to sense microbial products (pathogenassociated molecular patterns, PAMPs), NLRs, RLRs and AIM2 function as pathogen sensors in intra-cellular compartments. As explained in the text, all PPRs recognize also a class of signals in the form of cellular stressors collectively termed 'danger signals' or danger-associated molecular patterns (DAMPs). The figure shows the different classes of PRRs and some of the activating stimuli, in the form of PAMPs (infectious agents, viral and bacterial deoxyribonucleic acid [DNA]/ribonucleic acid [RNA]) or DAMPs ( $\mathrm{K}^{+}$efflux through pore protein, reactive oxygen species [ROS], lysosomal damage, with the consequent release of lysosomial enzymes such as cathepsin B). RLRs are a recently discovered group of PPRs involved in viral RNA recognition in the intra-cellular space, while AIM2 are able to sense cytoplasmic double-stranded DNA. NLR family comprises a large amount of intra-cellular PRR involved in the recognition of a huge amount of exogenous and endogenous ligands.

macrophages. ${ }^{42}$ Alongside, in a murine model of atherosclerosis, has been also shown that the activation of NLRP3 inflammasome by cholesterol crystals in macrophages involves lysosomal disruption and cytosolic release of cathepsin B and that cholesterol crystals itself can form from oxidized low-density lipoproteins, ${ }^{33}$ with a direct link between IL-1 $\beta$ synthesis by NLRP3 inflammasome and foam cell formation during early atherosclerosis. ${ }^{43}$ Recently, the CD36-mediated endocytic pathway has been identified as a master regulator of inflammasome activation in atherosclerosis. CD36 co-ordinates the intra-cellular conversion of soluble ligands, such as cholesterol or amyloid, to crystals or fibrils, resulting in lysosomal disruption and NLRP3 inflammasome activation. ${ }^{44}$ Moreover, atherosclerotic plaques of murine models expressed higher levels of the purinergic receptor $\mathrm{P}_{2} \mathrm{X}_{7}$, that binds extra-cellular adenosine triphosphate (ATP), which in turns acts as DAMP for intra-cellular sensors, promoting inflammasome activation. After high cholesterol diet, $\mathrm{P}_{2} \mathrm{X}_{7}$-deficient mice showed smaller atherosclerotic lesions and low grade inflammation essentially caused by caspase- 1 inhibition. ${ }^{45}$ Furthermore, since cholesterol crystals might induce inflammasome activation in a C5a-dependent manner, ${ }^{46}$ a novel field of research has been focused on complement system as innate immune mediator acting synergically with surface and intra-cellular PRRs recognizes dangerous stimuli and modulates inflammasome activation, ${ }^{47}$ with both activating ${ }^{48}$ and inhibiting properties. $^{49}$

Taken together, these experiments demonstrate that cholesterol is an endogenous DAMP able to prime NRLP3 inflammasome, and its deposition in the arteries might be an early cause rather than a late consequence of the chronic inflammation leading to atherosclerosis. Nevertheless, infectious agents can represent exogenous DAMPs and exert local pro-atherogenic effects by activating NLRP3 inflammasome in almost every cellular type within the plaque. In this way, NLRP3 might represent the cornerstone in the complex relationship between infections, immune response, vascular wall damage and atherosclerosis onset and progression. ${ }^{50}$

However, lot of evidence showed opposite effects of NLRP3, ASC and caspase-1 deficiencies on atherosclerosis. An experimental study on IL $1 r 1^{-1-} A p o e^{-I-}$ mice documented a surprising role of IL-1 in promoting plaque stability through the increase in smooth muscle cells and collagen content of the plaque. ${ }^{51}$ Another study on double knockout mice models demonstrated that the absence of NLRP3, ASC or caspase-1 does not influence atherosclerosis progression, plaque infiltration by macrophages and plaque stability. ${ }^{52}$ 


\section{a) INFLAMMASOME FORMING PROTEINS}

\section{b) NLRP3 ACTIVATION and IL-1 $\beta$ RELEASE}

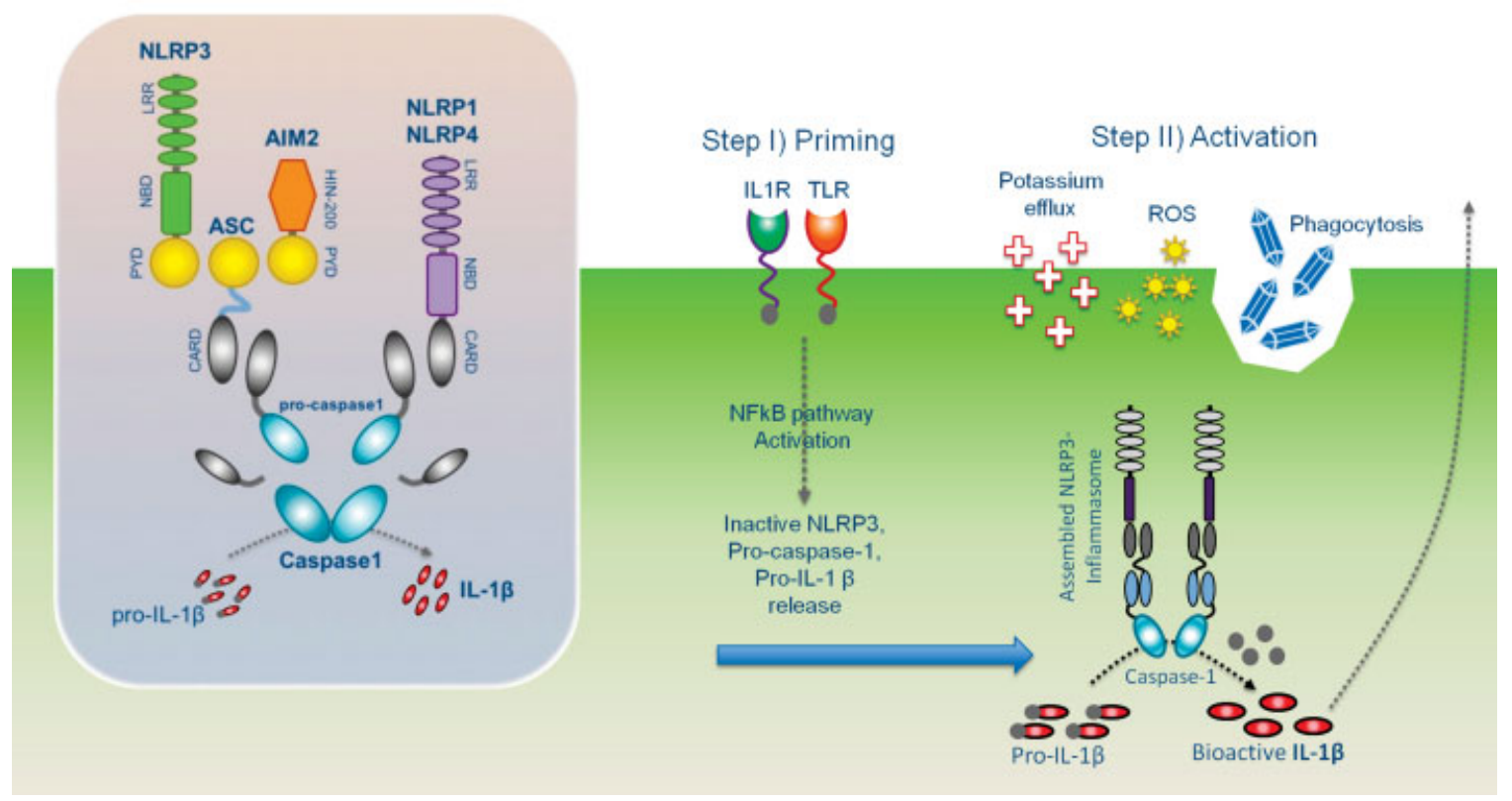

Fig. 2 Inflammasome forming proteins structure and inflammasome assembly. (A) Nucleotide-binding oligomerization domain (NOD)-like receptors (NLRs) consist of carboxy-terminal leucine-rich repeat (LRR) motifs, that are presumed to detect conserved microbial patterns and modulate NLR activity, an intermediary NOD domain, needed for nucleotide binding and self-oligomerization (NBD, nucleotide binding domain), and an amino-terminal region, consisting in protein-protein interaction domains, whose variability consents to distinguish four main classes of NLRs. Under resting conditions, NLRs are present in the cytoplasm in a repressed, inactive form. Upon stimulation, the receptors undergo a conformational change leading to the exposure of $\mathrm{N}$-terminal effector domain, which in turn induces the recruitment and activation of CARD (caspase-recruitment domain) and/or PYD (pyrin domain) containing effector molecules through homophilic CARD-CARD and/or PYD-PYD interaction. Pro-caspase-1 contains a CARD domain, thus NLRP1 and NLRC4, both containing CARD, are potentially able to directly recruit caspase-1. NLRP3, expressing PYD domains, requires the interaction with an adaptor protein containing both PYD and CARD domains, the apoptosis speck-like protein with CARD (ASC). As a member of interferon-inducible HIN-200 family, absent in melanoma 2 (AIM2) is the only inflammasome sensor that does not belong to the NLR family. Like NLRP3, this pattern recognition receptor (PRR) lacks CARD and requires the bridging protein ASC to recruit caspase-1. The exact role of ASC needs to be further elucidated, since this protein seems to interact also with CARD-containing receptors, in a fashion to modulate their activity and induce different intra-cellular pathways (i.e. pyroptosis vs. inflammation). (B) NLRP3 has been the most extensively studied inflammasome activator, due to the wide array of its microbial and non-microbial ligands. A first stimulus (step I) is mostly induced by membrane PRRs engagement and leads, through nuclear factor-kappa B (NF-kB) pathway activation, to the intra-cellular release of inflammasome-complex inactive precursors (pro-caspase-1, pro-IL-1 $\beta$, ASC protein and inactive form of NLRP3). Following an activating stimulus (probably sensed by LRR domain, step II), NLRP3 undergo conformational changes which in turns allow the recruitment, through homotypic pyrin domains (PYD-PYD) interactions, of the adaptor protein ASC, and finally, of caspase-1, which cleaves pro-IL-1 $\beta$ and proIL-18 into their bioactive forms. Given the huge number of potentially binding NLRP3 triggers, several studies have demonstrated that three possible pathways are involved in NLRP3 inflammasome activation: (1) $\mathrm{K}^{+}$efflux; through a purogenic $\mathrm{P}_{2} \mathrm{X}_{7}$-dependent pore protein in response to adenosine triphosphate (ATP), which acts as an NLRP3 agonist; (2) reactive oxygen species (ROS), in response to pathogen-associated molecular patterns (PAMPs) and/or danger-associated molecular patterns (DAMPs); and (3) lysosomal damage, with the consequent release of lysosomial enzymes, in response to phagocytosis of live or particulate pathogens. The latter mechanism has been used to explain the ability of crystals, such as monosodium urate and cholesterol crystals, in inducing inflammasome activation.

The reason for this discrepancy is unclear and the abovementioned notions deriving from animal studies need to be reinforced by other evidences. However, these data suggest that NLRP3 inflammasome and IL-1 might play different and sometimes opposite roles in distinct cell types during the different stages of atherosclerosis. ${ }^{53}$

IL-18 expression is also increased in human atherosclerotic lesions, ${ }^{54}$ with expression levels significantly higher in unstable compared with stable plaques. ${ }^{55}$ Lack of IL-18 has been associated to a reduced atherosclerotic burden in a mouse model of atherosclerosis. ${ }^{56}$ Besides in vitro and animal studies, also clinical data confirmed the association of elevated IL-18 levels with cardiovascular disease risk factors. ${ }^{57}$

\section{Inflammasome, Innate Immunity and Acute Coronary Syndromes}

Cholesterol crystals might also destabilize the plaque via NLRP3 inflammasome activation, IL-1 $\beta$ production and the associated local inflammatory response. ${ }^{58}$ In this model, plaque features are thought to be relevant, as plaques with large necrotic cores will release greater amounts of cholesterol crystals into the circulation causing more injury and arterial thrombosis. ${ }^{59}$ Systemically, IL-1 $\beta$ then induces IL-6, which elicits an acute-phase response in the liver, ${ }^{60}$ with the consequent release of acute-phase proteins. Among them, Creactive protein assessed by high-sensitivity assays (hs-CRP) is typically elevated in ACS and related to prognosis. This is 
not surprising as CRP is a prototypic marker of inflammation characterized by high sensitivity and a wide dynamic range. ${ }^{61,62}$ Thus, inhibition of inflammation by IL- $1 \beta$ antagonists or agents that dissolve or prevent cholesterol crystal formation may stabilize vulnerable plaques. In line with these evidences, a significantly higher systemic NLPR3 concentration has been shown in ACS patients, with a positive correlation with the extent of coronary atherosclerosis (assessed by different clinical scoring systems, such as SYNTAX, Clinical SYNTAX and Gensini), and with Global Registry of Acute Coronary Events and Thrombolysis in Myocardial Infarction risk score, suggesting a prognostic role of NLRP3 in ischemic patients, as an independent predictor of major adverse cardiovascular events (Major Adverse Cardiac Event [MACE], particularly 30 days' mortality). ${ }^{39}$ Our group recently demonstrated a higher expression of NLRP3 and pro-IL1 $\beta$ messenger RNA (mRNA) in samples of epicardial adipose tissue obtained at the time of cardiac surgery from patients presenting with ACS as compared with stable angina and mitral valve disease patients with no overt coronary disease. Moreover, we found that the pro-inflammatory response leading to NLRP3 and pro-IL1 $\beta$ expression could be the direct consequence of microbial colonization of epicardial adipose tissue. ${ }^{63}$ IL-1 $1 \beta$, IL-18 and caspase- 1 are highly activated following myocardial infarction (MI) and they might substantially contribute to post-ischemic remodeling. ${ }^{64}$ On the other hand, their deficiency is associated with an increased survival following experimental $\mathrm{MI},{ }^{65}$ and, in an in vivo animal model of AMI, the use of an IL-18 neutralizing antibody reduces the infarct size. ${ }^{66}$

The notion that innate immunity plays an important role in ACS is supported by the demonstration of activated monocytes, polymorphonuclear neutrophils (PMNs), eosinophils and mast cells not only at the site of plaque rupture, but also in the whole coronary circulation of patients with ACS. ${ }^{67}$ A high telomerase activity in PMNs coming from the culprit coronary plaque of patients with ACS has been demonstrated. This might represent a way to overcome replicative senescence, resulting in a prolonged survival and toxic potential of these inflammatory cells. ${ }^{68}$ Accordingly, we have shown a delayed apoptosis of peripheral PMNs in ACS patients. ${ }^{69}$ The role of PMNs has been further clarified in studies highlighting the prominent role of these cells in plaque instability: high levels of PMN-related biomarker myeloperoxidase has been associated with atherosclerosis and ACS, ${ }^{67,70}$ and several experimental models suggested a key role of this cell sub-set in plaque destabilization through endothelial erosion. ${ }^{71}$

Macrophages account for the majority of leukocytes in plaques. Most of plaque resident macrophages differentiate from monocytes recruited from circulating blood. However, monocytes represent a heterogeneous circulating population of cells, accordingly to their differential expression of CD14 and CD16. ${ }^{72}$ Human coronary artery lesions contain macrophage sub-populations with different gene expression patterns, which indicate heterogeneity. The canonical classification derived from in vitro studies states that this cell population can be functionally divided into two distinct groups, a pro-inflammatory phenotype, M1, involved in pro-inflammatory cytokines production and Th1 lymphocytes commitment, and M2 macrophages, with pre-eminent phagocytic activity, that mostly participate to tissue healing and inflammation dampening. ${ }^{73}$ Patients with coronary atherosclerosis have higher numbers of circulating $\mathrm{CD}_{14}{ }^{+} \mathrm{CD} 16^{+}$monocytes than healthy subjects and peak levels of $\mathrm{CD} 14^{\text {high }} \mathrm{CD} 16^{\text {low }}$ monocytes after AMI negatively correlate with the recovery of left ventricular ejection fraction (LVEF) 6 months after MI. ${ }^{74}$ Fluorescence-activated cell sorting analysis of coronary thrombi obtained during primary percutaneous coronary intervention (pPCI) revealed a greater proportion of $\mathrm{CD} 14^{+}$cells in thrombi as compared with aortic blood. Moreover, monocytes accumulated within thrombi specifically over-express TLR-4, together with specific patterns of locally expressed chemokines and cytokines as compared with circulating monocytes. $^{75}$ Interestingly, interferon (IFN)- $\alpha$, produced by dendritic cells in atherosclerotic plaques, could enhance TLR-4 signalling by sensitizing these cells to lipopolysaccharides and other microbial molecules but also to modified endogenous molecules, all abundantly present in the atherosclerotic lesion micro-environment. These sensitized APCs strongly up-regulate the production of cytokines such as TNF- $\alpha$, IL-12, IL-23 and MMP-9, thus enhancing plaque instability. ${ }^{76}$

\section{Inflammasome, Innate Immunity and Post-Infarction Remodelling}

It is well recognized that maladaptive ventricular remodelling, leading to HF, can be a consequence of a dysregulated inflammatory process. Cardiac fibroblasts are the most represented cell population in the heart and their role is not only confined to myocardial fibrosis. By releasing proinflammatory cytokines in response to danger signals, they might modulate the crosstalk between innate immune system and surrounding cells, including cardiomyocytes, vascular cells and peripheral inflammatory cells. ${ }^{77}$ NLRP3, IL-1 $\beta$ and IL-18 mRNA expression levels are significantly up-regulated in myocardial fibroblasts of adult mice following infarction, suggesting that NLRP3 inflammasome is one of the key mediators of myocardial ischemia/reperfusion (I/ $\mathrm{R}$ ) injury and infarct size. ${ }^{78}$ NLRP3 inflammasome is one of the major cytosolic danger sensors in cardiomyocytes, and endogenous IL- $1 \beta$ and IL-18 play a significant role in I/Rinduced human myocardial injury. ${ }^{79}$ Indeed, caspase- 1 inhibition prevents ischemia-induced myocardial dysfunction in in vitro models of human atrial myocardium. ${ }^{80}$ Patients with ischemic HF have increased IL-18 circulating levels that positively correlate with a worse outcome. ${ }^{81}$ Moreover, a correlation between infarct size, inflammasome activation and IL- $1 \beta$ production during myocardial $I / R$ injury has been demonstrated in vivo, together with the reduction of infarct size after $I / R$ in mice after the administration of NLRP3 inflammasome inhibitors. ${ }^{82,83}$ Several mechanisms are involved in NLRP3 inflammasome activation in failing cardiac fibroblasts: ATP-induced $\mathrm{K}^{+}$efflux, translocation of mitochondrial DNA (from the nucleus to 
the cytoplasm) and production of ROS. Mitochondrial integrity in cardiac cells seems to be the key limiting factor of inflammasome activation, since a defective intra-cellular clearance of damaged mitochondria could be responsible of NLRP3 inflammasome up-regulation in failing cardiomyocytes. $^{84}$ On the other hand, it is well known that IL- $1 \beta$ has a direct effect as a 'myocardial depressant factor', able to directly impair myocardial contractility and relaxation through different mechanisms, such as calcium-channel inhibition, ${ }^{85}$ uncoupling of $\beta$-adrenergic receptors from the adenylyl cyclase, ${ }^{86}$ down-regulation of phospholamban and sarco/endoplasmic reticulum $\mathrm{Ca}^{2+}$-ATPase ${ }^{87}$ and nitric oxide synthase-enhanced expression. ${ }^{88} \mathrm{~A}$ very recent work by van Hout et al demonstrated that pigs undergoing balloon coronary occlusion and subsequent treatment with a specific NLRP3 inhibitor showed a smaller infarct size, a markedly preserved ejection fraction and a lower neutrophil influx as compared with non-treated animals, thus confirming the detrimental effects of IL- $1 \beta$ and IL-18, whose levels were also dose-dependently reduced in treated pigs. ${ }^{89}$

According to this 'inflammatory hypothesis', modulation of the inflammasome may therefore represent a therapeutic strategy to limit cell death and prevent HF after AMI. At this regard, it is also of interest that other members of the IL-1 family, such as IL-33, might have instead cardioprotective role in the infarct healing, by promoting dendritic cells and M2 macrophages activity and by inhibiting myocytes apoptosis. IL-33, differently from IL-1 and IL-18, is biologically active in its full-length form of $31 \mathrm{kDa}$ and its production is independent from inflammasome activation; however, caspase- 1 seems to be involved in the cleavage of this molecule leading to the release of an inactive form. ${ }^{90}$ Thus, a more profound comprehension of these pathways will probably consent to modulate, through specific therapeutic tools, inflammasome and caspase activity towards cardioprotective routes. ${ }^{21,91}$

\section{Adaptive Immunity in Cardiovascular Disease}

The presence of leucocytes within the atherosclerotic plaque was demonstrated in the late 1970s, after the discovery of lipid-laden foam cells derived from macrophages in the same site. The detection of human leukocyte antigen molecules in plaques and the subsequent discovery of $\mathrm{T}$ cells some years later suggested that cellular immune responses in the vessel wall could be also possibly involved in atherogenesis and in the progression of the disease. ${ }^{92}$ Around $70 \%$ of T lymphocytes populating atherosclerotic plaques are $\mathrm{CD} 4{ }^{+} \mathrm{T}$-helper (Th) cells. Most of these cells belongs to type 1 pro-inflammatory Th 1 sub-set and expresses pro-atherogenic cytokines such as IFN- $\gamma$ and TNF. ${ }^{93}$

\section{T-Lymphocytes and Plaque Formation}

The importance of Th1 cells in atherosclerosis has been documented in several studies, both in experimental animal models and in humans. ${ }^{94-96}$ Absence of $\mathrm{CD}^{+}$Th cells, deficiency of Th1-cytokine INFY or deletion of the Th1 transcription factor T-bet in mice leads to reduction in plaque size and atherosclerotic burden. ${ }^{97-99}$ Conversely, the role of Th2 sub-set and its related cytokines in atherosclerosis is still controversial, with both pro-atherogenic and protective effects documented. ${ }^{100,101}$ Recently, the Th1/ Th2 paradigm of Th cell differentiation has been expanded following the discovery of $\mathrm{CD} 4{ }^{+} \mathrm{CD} 25^{+}$regulatory $\mathrm{T}$ cells (Tregs) and effectors Th cells producing IL-17 (Th17), described as two distinct lymphocyte sub-sets. Overall, the former exhibit immunosuppressive properties and represent the master modulators of inflammatory responses, while Th17 seem to have mainly a pro-atherogenic role; nevertheless, an atheroprotective function has been recently documented. Tregs are found in affected arteries wall, representing approximately 1 to $5 \%$ of the localized $\mathrm{T}$ cell population within atherosclerotic plaque. Impairment in number or function of Tregs could induce plaque formation and progression of atherosclerotic disease. ${ }^{102,103}$ In other studies, apolipoprotein $\mathrm{E}(\mathrm{ApoE})^{-1-}$ mice showed increased atherosclerotic lesion size and increased vulnerability after the depletion of peripheral Tregs by anti-CD25 monoclonal antibodies. ${ }^{104}$ Conversely, a decreased size of atherosclerotic lesions in $\mathrm{ApoE}^{-1-}$ mice receiving adoptive transfer of Tregs has been shown compared with $\mathrm{ApoE}^{-1-}$ mice treated with phosphate buffer saline or effector $\mathrm{T}$ cells. ${ }^{105,106}$ Anti-atherogenic effects have been also showed for Tregs' hallmark cytokines transforming growth factor (TGF)- $\beta$ and IL-10. ${ }^{107,108}$

Th17 lineage, expressing RORYt as transcription factor, differentiates from naïve $\mathrm{CD} 4^{+} \mathrm{T}$ cells upon TGF- $\beta$, IL-23 and IL-6 stimulation. IL-17, primarily produced by Th17, induces pro-inflammatory cytokines release and neutrophils mobilization. The role of Th17 lymphocytes in atherosclerosis remains controversial. Increased levels of Th17 and Th17-associated cytokines, such as IL-17, IL-21 and IL23 , have been described in atherosclerotic carotid artery plaques and have been associated with the progression of atherosclerotic disease and with plaque vulnerability. ${ }^{109,110}$ Other studies reported that patients with ACS showed a significant increase in peripheral Th17 cells, Th17-related cytokines and iROR- $\gamma t$ expression, as compared with stable angina (SA) patients and healthy controls. The increase in circulating levels of Th17 paralleled a reduction in peripheral Tregs, Treg-related cytokines and forkhead box P3 (FoxP3) expression. ${ }^{111-113}$ However, some recent studies reported different outcomes. Taleb et al documented an association between IL-17 expression in human carotid artery plaques and plaque stability. ${ }^{114}$ Brauner et al have recently confirmed these data by demonstrating that IL-17 is linked to increased collagen content in atherosclerotic plaque. ${ }^{115}$ More recently, lower levels of circulating IL-17 have been associated with a worse outcome at 2 years' follow-up in a large population of patients admitted for AMI. ${ }^{116} \mathrm{~A}$ mechanistic explanation for these discrepancies is still lacking; however, the controversial results of the above-mentioned studies could be at least in part explained by the astonishing flexibility of Th17 sub-set. ${ }^{117}$ 


\section{T-Lymphocytes and Acute Coronary Syndromes}

Overall, about half of patients with ACS and systemic evidence of inflammation have a skewed $\mathrm{T}$ cell differentiation oriented towards aggressive effector phenotypes and defective Tregs. ${ }^{96}$ In this sub-set of ACS patients, helper T cell dysregulation might affect the biological outcome of the immune response and contribute to plaque destabilization through multiple damaging pathways. ${ }^{94}$ In ACS patients, helper $\mathrm{T}$ cell abnormalities are associated with worse outcomes, especially in patients with diabetes mellitus. ${ }^{94,96,118}$ Moreover, CD4 ${ }^{+}$T-cells from ACS patients show enhanced response to $T$ cell receptor (TCR) stimulation and have a lower setting of the $\mathrm{T}$ cell activation threshold, attributable to enhanced amplification of proximal TCR-mediated signals. ${ }^{119,120}$ Intriguingly, some of these abnormalities are confined to the acute phase of ACS, whereas others persist during the stable phase of the disease, suggesting the existence of a deep-seated lymphocyte hyper-reactivity that may abruptly degenerate to cause an inflammatory outburst. The molecular TCR signalling alterations observed in ACS include an increase in the positive activation signals with higher accumulation of CD3 complexes and zeta-chain associated protein kinase of $70 \mathrm{kD}$ (Zap70) in the immunological synapse during antigen presentation, higher early tyrosine phosphorylation after TCR stimulation and a defective deactivation of the lymphocyte-specific protein tyrosine kinase (LCK). On the other hand, ACS patients exhibit reduced activity of the inhibitory molecular patterns such as reduced phosphorylation of Zap70 at its inhibitory residue Tyr-292, lower expression of PECAM-1, a molecule implicated in down-modulation of $\mathrm{T}$ cell activity and reduced activation of cyclic adenosine monophosphate response element binding, a transcription factor believed to be particularly important for the generation and maintenance of Treg and for IL-2 and IL-10 production. ${ }^{119}$ Finally, ACS patients show enhanced expression of the protein tyrosine phosphatase non-receptor type 22, an enzyme playing a key role in controlling the intensity of the early TCR signal transduction acting on LCK and on Zap70. ${ }^{120}$ Overall, the lower setting of T cell activation threshold could affect the direction of $\mathrm{T}$ cell differentiation leading to the unbalanced helper $\mathrm{T}$ cell subset expansion observed in ACS patients. ${ }^{94}$

\section{IL-1, Innate-Adaptive Immunity Crosstalk and Cardiovascular Disease}

In immune response, the innate recognition of an altered homeostasis (tissue damage, infections) is the first step to generate an effective adaptive immunity. Understanding the crosstalk between the two arms of immune response represents a crucial point to explain the pathophysiology of chronic inflammatory and autoimmune diseases. Recent evidences described a possible role of inflammasome in providing instruction to the adaptive immune system, and even if IL-1 represents only one of multiple factors required for mounting effective lymphocytes activation, its role on specific $\mathrm{CD} 4^{+} \mathrm{T}$ cell sub-set has become recently more clear. Animal models demonstrated that lymphocyte sensitization was dampened in inflammasome-deficient mice. ${ }^{121}$ It has also been shown that ATP released by dying tumour cells activates NLRP3 in dendritic cells, and the release of IL- $1 \beta$ is sufficient to drive an adaptive anti-tumour immunity. ${ }^{122}$ Several studies explored the crosstalk between inflammasome and $\mathrm{T}$ cell responses in autoimmune disease, with conflicting results. ${ }^{123-125}$ Very recently, a direct role for NLRP3 in human adaptive immune cells has been described, as it has been shown that NLRP3 inflammasome assembles in human $C D 4^{+} T$ cells and initiates caspase-1-dependent IL-1 $\beta$ secretion, thereby promoting IFN- $\gamma$ production and Th-1 differentiation in an autocrine manner. Aberrant NLRP3 activity in $\mathrm{T}$ cells affects inflammatory responses in human auto-inflammatory disease and in mouse models of inflammation and infection. Together, these data demonstrate that human $\mathrm{CD} 4^{+} \mathrm{T}$ cells produce IL-1 $\beta$ in an NLRP3-dependent manner, autocrine IL- $1 \beta$ generation supports IFN- $\gamma$ secretion and dysregulation of this pathway occurs in human autoinflammatory disease. Thus, NLRP3 inflammasome activity is not confined to 'innate immune cells' but is an integral component of normal adaptive Th1 responses. ${ }^{126}$ Given the ability of IL-1 $\beta$ and inflammasome in driving adaptive immunity responses, it is conceivable that a similar crosstalk could be involved in CAD as well. An altered adaptive immune response is indeed one of the hallmarks of CAD. The exact role of IL- $1 \beta$ and inflammasome in providing instruction to the adaptive immune system in the specific setting of atherosclerosis, from plaque formation to ACS, needs to be further elucidated in targeted studies. However, a wide amount of evidences demonstrates an imbalance in $T$ cell sub-sets both in stable CAD and in ACS on one hand (see above), and a crucial role of IL- $1 \beta$ in inducing the differentiation of $T$ cell sub-sets towards those phenotypes expanded in CAD, on the other hand (-Fig. $\mathbf{3}$ ).

As described for other inflammatory and autoimmune diseases, the imbalance of adaptive immunity found in atherosclerosis can be at least in part explained by different environmental conditions leading to inappropriate effector $\mathrm{T}$ cells activation and impaired Tregs number and/or function. $\mathrm{T}$ lymphocytes show a great degree of flexibility, and robust evidences widely demonstrated that their differentiation is strictly dependent on the balance between polarizing cytokines rather than on their absolute amount. In the contest of atherosclerosis, it is possible that IL- $\beta$ may act directly in target tissues, such as vessel wall and atherosclerotic plaque, increasing $T$ cell activity in synergy or antagonism with other factors known to modulate inflammation. ${ }^{127} \mathrm{~A}$ higher expression of inflammasome-related genes has been described in $\mathrm{CD}_{4}{ }^{+} \mathrm{CD} 28^{\text {null }} \mathrm{T}$ cells, a long-lived $\mathrm{Th} 1$ cell sub-set characterized by an aggressive effector phenotype and associated with worse outcomes in ACS. This represents a pre-activation state that leads to an increased release of IL$1 \beta$ upon cell activation and contributes to the functional properties of $\mathrm{CD} 4{ }^{+} \mathrm{CD} 28^{\text {null }} \mathrm{T}$ cells.

IL-1 $\beta$ through IL-1R signalling can provide a survival signal to naïve $T$ cells, causing a transient release of the survival cytokine IL-2 from $T$ cells and up-regulating IL-2R surface expression. Furthermore, IL-1 $\beta$ is actively involved in 


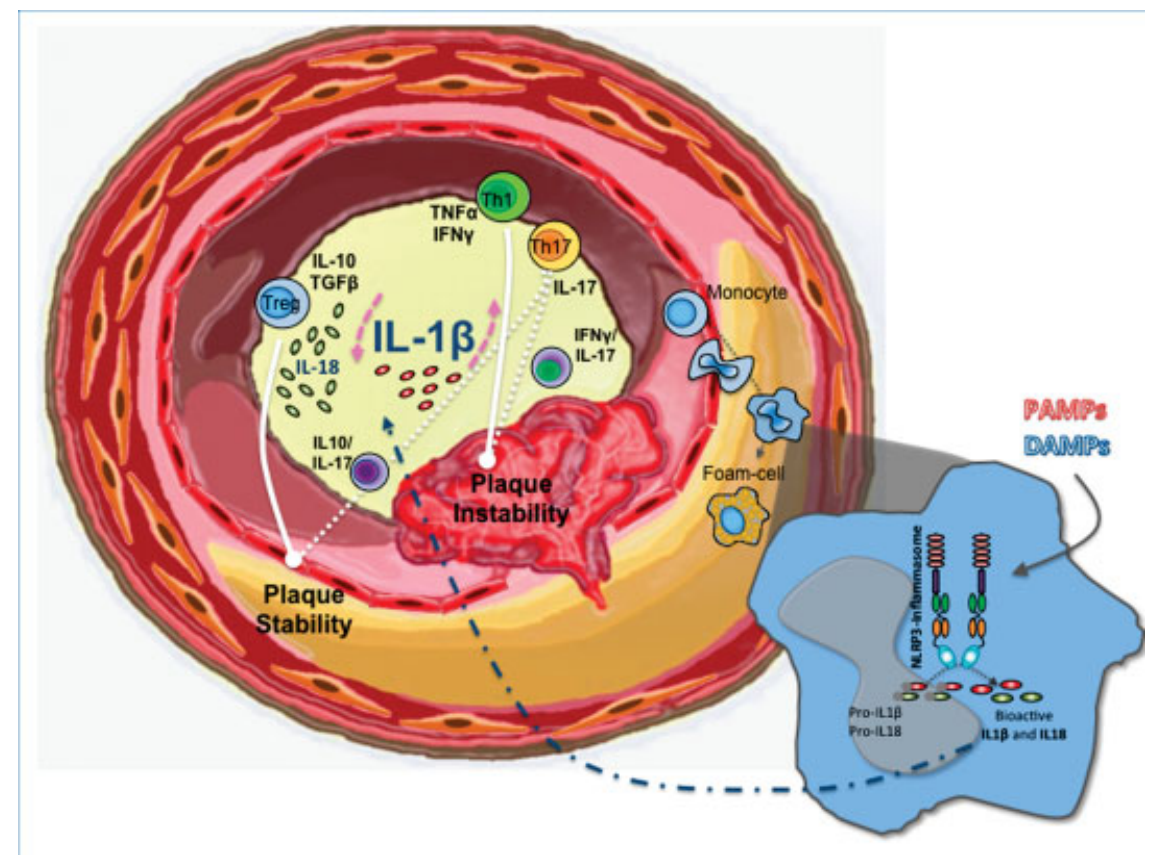

Fig. 3 Innate-adaptive immunity crosstalk and plaque instability. Around 70\% of T lymphocytes populating atherosclerotic plaques are CD4 ${ }^{+} \mathrm{T}-$ helper cells. Most of these cells belongs to type 1 pro-inflammatory T-helper (Th1) sub-set and expresses pro-atherogenic cytokines such as interferon-y (IFN- $-\gamma$ ) and tumour necrosis factor (TNF- $\alpha$ ). Regulatory T cells (Tregs) exhibit immunosuppressive properties and represent the master modulators of inflammatory responses, with a prevalent anti-atherogenic effect (interleukin (IL)-10 and transforming growth factor (TGF)- $\beta$ production). Th17 seem to have mainly a pro-atherogenic role; however, an atheroprotective function has been also recently documented. This might be a direct consequence of the flexibility of Th17 cell lineage: indeed, in different environmental circumstance Th17, even representing a specific and distinct cell lineage, acquire features overlapping both with inducible Tregs (IL-17/IL-10 dual producing T cells) and with Th1 (IL-17/IFN-y dual producing T cells), thus encasing a pro- or anti-atherogenic effect as response to different cytokine milieu. Since the imbalance of adaptive immunity found in atherosclerosis can be at least in part explained by different environmental conditions, it is possible that IL-1 $\beta$ may act directly in target tissues, such as vessel wall and atherosclerotic plaque, modulating T cell activity in synergy or antagonism with other factors known to modulate inflammation. Increasing evidences documented a direct role of inflammasome activation and IL-1 $\beta$ from plaque formation to plaque instability and adverse cardiac remodelling after myocardial infarction leading to heart failure. In the right side bottom of the figure, a model of NLRP3 inflammasome activation with the subsequent release of bioactive IL-1 $\beta$ and IL-18, both involved in the onset and progression of atherosclerotic disease.

the maintenance of $\mathrm{CD}^{+}$memory $\mathrm{T}$ cells and in the interaction between $\mathrm{T}$ - and B-lymphocytes, with the subsequent production of high-affinity antibodies. IL-1 $\beta$ signalling allows for a breach in tolerance through expansion of conventional T cells even in the presence of Tregs. Recent studies indicate that IL-1 $\beta$ plays a critical role in early Th17 cell differentiation. ${ }^{128-130}$ Sutton et al showed that IL-1 receptor expression in T cells, induced by IL-6, is necessary for the induction of experimental autoimmune encephalomyelitis and for early Th17 cell differentiation in vivo. ${ }^{128}$ Moreover, $\mathrm{CD}^{+} \mathrm{T}$ cells primed by NLRP3-activated antigen presenting cells up-regulate chemotaxis-related proteins (such as CCR2 and CXCR6), resulting in T cell migration in the same model of experimental autoimmune encephalomyelitis. ${ }^{131}$ Increased levels of Th17 in IL-1 $\mathrm{Ra}^{-1-}$ mice have been demonstrated, with the consequent development of rheumatoid arthritis, suggesting that IL-1 is the driving force behind the IL-17producing Th17 cells. ${ }^{132}$ In human immune system, Th17 cells can shift to a Th17/Th1 phenotype upon specific stimulation by IL-1 $\beta$. The presence of IL-17/IFN- $\gamma$ dual producing cells, expressing T-bet and RORYt transcription factors has been described within atherosclerotic plaque, together with a synergistic pro-inflammatory effect of IL-17 and IFN- $\gamma$ on vascular wall. Moreover, upon T cell stimulation in the presence of pro-inflammatory cytokines, such as IL-1 $\beta$, IL-2, IL-21 and IL-23, Tregs can differentiate into IL-17 producing cells, expressing RORYt and FoxP3 transcription factors. The exact role of IL-17 producing Tregs in the setting of atherosclerotic disease is still not clear; however, they seem to be involved in controlling the Th17/Treg balance, which is altered in atherosclerosis and even more in ACS. Mercer et al pointed out a higher expression of the inflammatory cytokine receptors IL-1R1 and high levels of mRNA for IL-1Ra on resting mature Tregs compared with naïve or memory $\mathrm{T}$ cells. Moreover, they found that the decoy receptor for IL-1 (IL-1R2), that specifically binds IL-1 and reduces its activity, is not expressed by any of the resting T cells but is rapidly upregulated and preferentially expressed on Tregs upon TCR stimulation. ${ }^{133}$ These data prove a direct role of Tregs in dampening effector $\mathrm{T}$ cell activation and pro-inflammatory responses through the attenuation of IL-1 $\beta$ activity. The involvement of inflammasome in the crosstalk between innate and adaptive immunity is also suggested by the immune properties of IL-18. This cytokine is able to induce IFN- $\gamma$ production in Th1 and natural killer cells, to activate $\mathrm{NF}-\mathrm{kB}$ and to increase Fas ligand and chemokine expression. As IFN- $\gamma$ inducing factor, IL-18 is involved in the activation of macrophages, in the induction of class I and II major 
histocompatibility complex molecules and in Th1 cell polarization, thus representing a strong regulator of the adaptive immune response. $^{134}$

IL- $1 \beta$ significantly affects the cross-talk between blood platelets and the immune response system, primarily inducing the formation of blood platelet-leukocyte aggregates. Megakaryocyte maturation and RNA production are altered by IL1 $\beta$ and IL1R1. Platelet function is enhanced through p38 mitogen-activated protein kinase signalling pathway on IL1 $\beta$ stimulation. In particular, IL1 $\beta$ and IL1R1 increase platelet adhesion and heterotypic aggregate formation both in the setting of inflammation, high fat diet and bacterial infection, which are reversed in IL1R $1^{-1-}$ and IL1 $\beta^{-1-}$ mouse models. Therefore, IL1 $\beta$, through IL1R1, promotes pro-inflammatory functions in both megakaryocytes and platelets that may contribute to the development of atherothrombotic diseases. ${ }^{135}$

\section{Targeting Inflammasomes in Cardiovascular Disease: State of the Art}

The involvement of NLRP3 inflammasome in a wide range of diseases makes this intra-cellular platform a desirable molecular target. To this end, several pharmacological NLRP3 inflammasome inhibitors have been tested in murine models, including small-molecule inhibitors (such as $\beta$-hydroxybutyrate), autophagy inducers agents (resveratrol and others) and microRNA (miR-223). All these agents are able to inhibit NLRP3 complex activation at different levels of inflammasome assembly. However, to date, only type 1-IFN $(\alpha$ and $\beta$ ) have been approved in clinical practice for the treatment of specific autoimmune and auto-inflammatory disease. ${ }^{136}$ As shown above, since IL- 1 represents the final mediator of NLRP3 inflammasome activation, this cytokine has been widely investigated as molecular target to prevent or dampen its detrimental effects in CAD. ${ }^{137,138}$

To date, IL-1 blocking drugs approved by Food and Drug Administration are: anakinra, a recombinant human IL-1Ra, able to inhibit both IL- $1 \alpha$ and IL-1 $\beta$; rilonacept, a recombinant fusion protein able to bind both soluble IL- $1 \alpha$ and IL- $1 \beta$ and IL-1R; and canakinumab, a specific monoclonal IL-1 $\beta$ antibody that bind irreversibly to circulating human IL- $1 \beta$ and prevents activation of the IL-1 receptor, without interfering with IL- $1 \alpha$ activity. - Table 3 presents an overview of the principal clinical trials.

The MRC-ILA-HEART study was a double-blinded, placebo-controlled trial in which 186 patients with non-STelevation MI were recruited within 48 hours of symptom onset and randomly assigned to anakinra $100 \mathrm{mg}$ subcutaneous daily or placebo for 14 days. Even if the primary endpoint of the study was reached (a statistically significant reduction of hs-CRP levels within the first week), anakinra treatment did not demonstrate to reduce troponin T levels and to influence infarct size. Conversely, this therapy was associated with increase in MACE at 12-month follow-up. ${ }^{139}$

Intriguingly, Abbate et al obtained conflicting results in two previous small pilot studies: the Virginia Commonwealth University-Anakinra Remodeling Trial (VCU-ART) and VCU-ART2. ${ }^{140,141}$ These studies included a total of 40 patients, admitted to the coronary care unit for ST-elevation MI (STEMI), undergoing $\mathrm{pPCI}$, and randomly assigned to anakinra $100 \mathrm{mg}$ daily or placebo for 14 days. Anakinratreated patients experienced no MACE, demonstrating an acceptable safety profile of this drug. Moreover, the treatment in patients with re-perfused STEMI was associated with a significant blunting of inflammatory response (significant reduction in CRP levels), with a more favourable left ventricular remodelling on cardiac magnetic resonance imaging (trend), and with a reduced rate of new-onset HF at 3 months. No differences in infarct size and in recurrence of ACS were detected in anakinra-treated patients. ${ }^{140}$ These promising findings were consistent with those obtained in previous pre-clinical murine models ${ }^{142}$ and paved the way for additional clinical trials aimed to further elucidate the IL1 targeting in the setting of ACS. To this end, the VCU-ART3 trial is an on-going phase II study ${ }^{143}$ in which 99 patients with re-perfused STEMI will be enrolled and randomly assigned to standard (100 $\mathrm{mg}$ daily) versus high dose (100 mg twice daily) of anakinra, with a 1-year follow-up.

In the setting of ACS, increased soluble IL-1 plasma levels can be detected and might be involved in the maladaptive ventricular remodelling leading to HF. Ikonomidis et al in 2008 demonstrated the beneficial effect of blocking IL- 1 on the entire cardiovascular system. A total of 23 patients with rheumatoid arthritis without $\mathrm{HF}$ were subjected to a single injection of anakinra $(150 \mathrm{mg})$. A significant improvement in parameters of myocardial contractility (left ventricular function) and relaxation (E/E' ratio), coronary flow reserve (assessed by echocardiography) and endothelial function (measured by brachial artery flow-mediated dilatation) was observed within 3 hours of the administration of anakinra and after 1 month of follow-up. A parallel group of patients treated with triamcinolone experienced no analogue beneficial effects. ${ }^{144}$

The Acute Inflammatory Response in Heart Failure trial was an open-label, single arm pilot study in which 7 patients with HF with reduced ejection fraction (LVEF $<40 \%$ ) and high levels of inflammatory markers (CRP $>2 \mathrm{mg} / \mathrm{L}$ ) were enrolled and treated with anakinra $100 \mathrm{mg}$ daily for 14 days. IL-1ß blocked treatment lead to a significant improvement in exercise capacity, assessed by cardiopulmonary test at baseline and after 14 days of treatment. Moreover, a significant blunting of inflammatory markers was documented, with a reduction of CRP and IL-6 levels of $84 \%$ and $90 \%$, respectively. ${ }^{145}$

The Diastolic Heart Failure Anakinra Response (D-HART) trial is a recent pilot study based on the hypothesis that blocking IL-1 $\beta$ pathway might produce beneficial effects also in patients with HF with preserved ejection fraction. A 14day treatment with anakinra $100 \mathrm{mg}$ daily in a cohort of 12 patients was associated with a significant improvement in exercise capacity, assessed by peak of oxygen consumption at cardiopulmonary test, and with a significant reduction of CRP plasmatic levels. ${ }^{146}$ More recent phase II clinical trials on this field, such as the completed RED-HART trial ${ }^{147}$ and the D-HART2 trial, ${ }^{148}$ will probably provide an important contribution in the treatment of HF. 


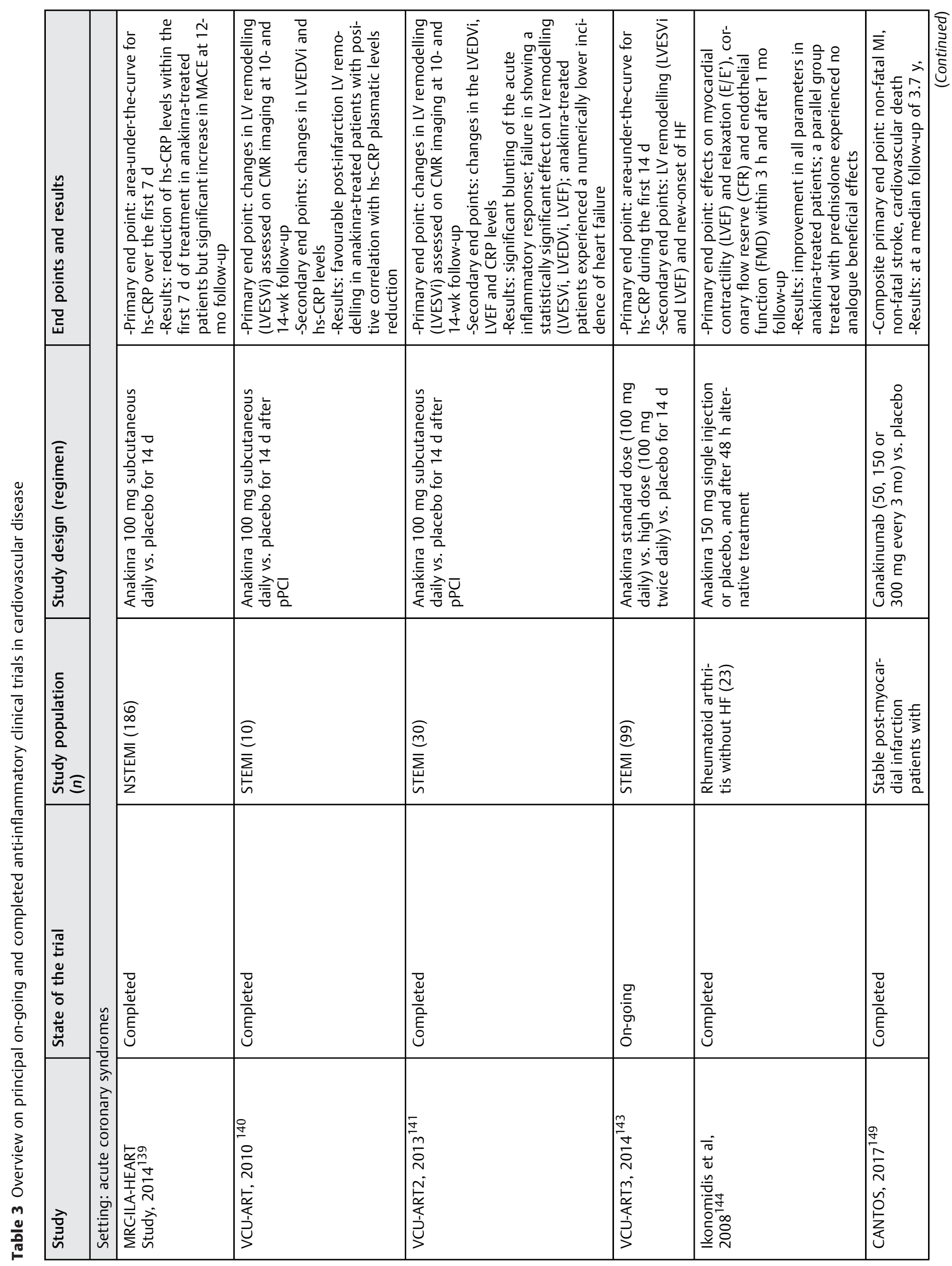




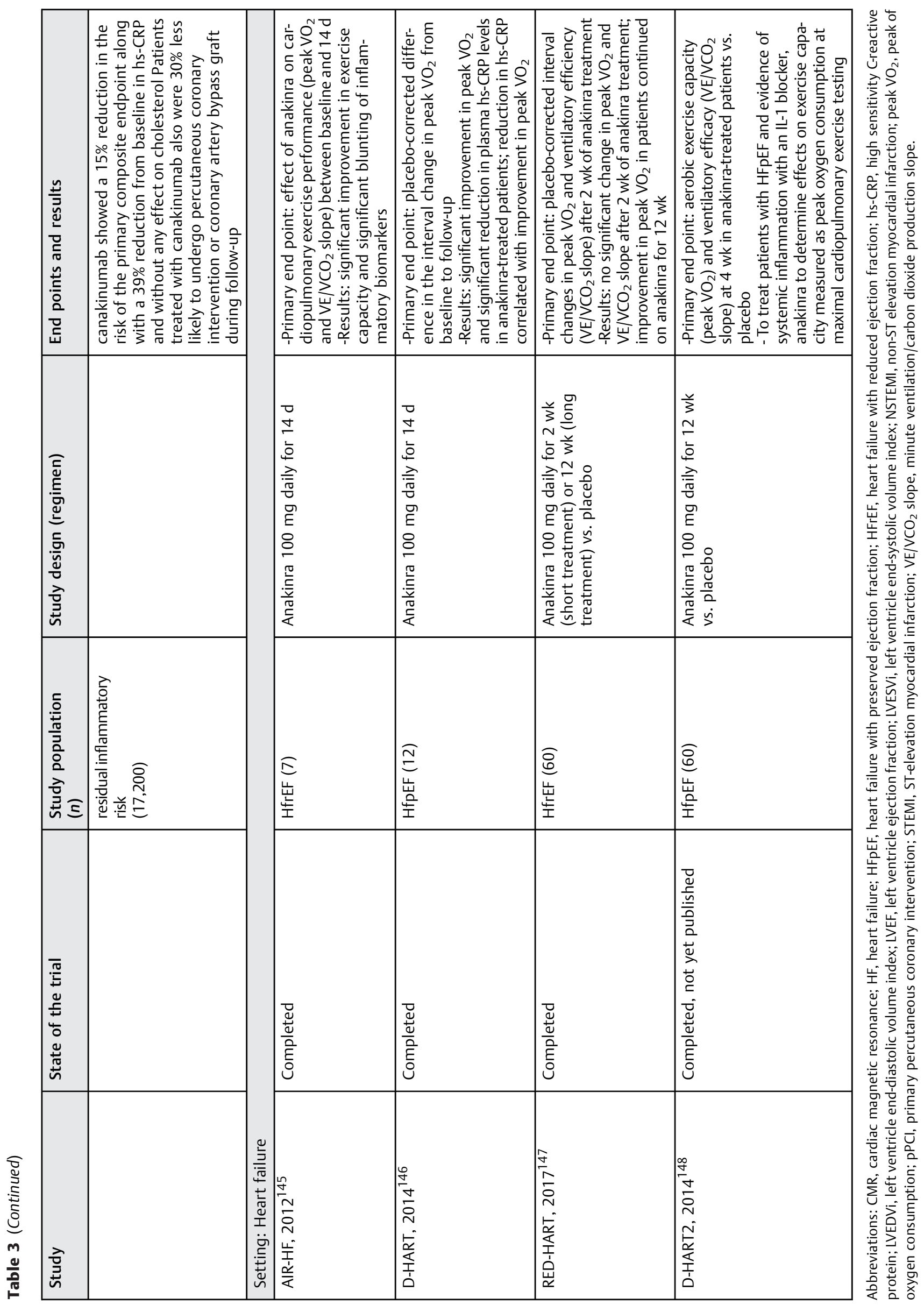


Despite the potential exciting clinical implications of the above-mentioned studies, the greater part of them is underpowered due to the relative small number of recruited patients. This point might explain at least in part conflicting or inconclusive results.

Besides these, the results of Canakinumab Anti-Inflammatory Thrombosis Outcomes Study (CANTOS) trial have been recently released. CANTOS is a phase III, randomized, placebo-controlled trial aimed at evaluate the potential additional beneficial role of IL- $1 \beta$ inhibition for the prevention of recurrent cardiovascular events among patients with stable CAD who remain at high vascular risk due to persistent elevated hs-CRP levels. ${ }^{149}$ At a median follow-up of 3.7 years, canakinumab at 150 and $300 \mathrm{mg}$ once every 3 months showed a $15 \%$ reduction in the risk of the primary composite efficacy endpoint of non-fatal MI, non-fatal stroke or cardiovascular death, compared with placebo-treated patients, along with a 39\% reduction from baseline in hs-CRP levels, without any effect on cholesterol. Patients treated with canakinumab also were $30 \%$ less likely to undergo PCI or coronary artery bypass graft during follow-up. In a secondary analysis of CANTOS trial, Ridker et al found that trial participants randomized to canakinumab who achieved hs-CRP concentrations $\leq 2 \mathrm{mg} / \mathrm{L}$ had a $25 \%$ reduction in MACE and a $31 \%$ reduction in cardiovascular mortality and all-cause mortality, whereas no significant benefit was observed among on-treatment patients with hs-CRP concentrations of $2 \mathrm{mg} / \mathrm{L}$ or above. ${ }^{150}$ Even if the beneficial effects of canakinumab administration needs to be examined alongside with the increased risk of infection of patients undergoing such powerful anti-inflammatory treatment, these data provide the first proof that inflammation inhibition in the absence of lipid lowering can improve CAD outcomes, thus moving the inflammatory hypothesis of CAD forward scientifically. ${ }^{151}$

\section{Conclusion and Future Perspectives}

Robust evidences support the inflammatory nature of atherosclerosis. Based on several data, atherosclerosis could be considered as a consequence of an altered innate-adaptive crosstalk, rather than an inflammatory disease in which the two arms of immunity act separately and in different moments. In this setting, inflammasome activation, resulting from the recognition of a large variety of stimuli, is a pivotal mechanism of innate immunity leading to quantitatively and/or qualitatively inappropriate elicitation of adaptive responses within the vascular wall. According to this intriguing hypothesis, inflammasome activation, as an early, non-specific but strong response, could be seen as the common pathway on which a huge number of endogen and external stimuli implicated in atherogenesis may converge.

Studies on the early plaques demonstrated an involvement of inflammasome from the first phases of plaque formation, showing how the deposition of cholesterol crystals in the artery wall and the consequent NLRP3 activation, might be considered as an early cause, rather than a late consequence of chronic inflammation. In the same way, inflammasome activation triggered by various infectious agents or other cell-damaging stressors could be an early step in plaque progression. The hypothesis that inflammasome activation is also involved in atherothrombosis and ACS needs to be confirmed in targeted studies, while increasing evidences from clinical studies highlights a pivotal role of IL1 in the adverse cardiac remodelling after an AMI.

This hypothesis recently received an important proof-ofconcept thanks to the results of the first mega-trial on antiinflammatory treatment with canakinumab (CANTOS), a human monoclonal antibody against IL-1 $\beta$, in patients with previous MI and 'residual inflammatory risk', as documented by persistently high hs-CRP levels. Nevertheless, the demonstrated absolute clinical benefit of canakinumab cannot justify its routine use in patients with previous MI and residual inflammatory risk, identified as hs-CRP $\geq 2$ $\mathrm{mg} / \mathrm{L}$, until we understand more about the mechanisms responsible for coronary instability, the efficacy and safety trade-offs and unless a formal cost-effectiveness evaluation supports it.

Many different stimuli have been studied in relationship with atherosclerotic plaque formation and instability, each of them probably accounting for a small part of the process or relevant for a subset of CAD patients only. Given the epidemiologic burden of atherosclerotic disease, the individuation of key mechanisms of atherosclerosis onset and progression is of paramount importance; in this setting, further studies on early innate response and the innate-adaptive crosstalk may provide essential information on the pathogenesis of the disease, and may help individuating therapeutic tools to delay the chronic progression and prevent the acute destabilization of atherosclerotic plaque.

\section{Funding}

This work was partially supported by the Catholic University of the Sacred Heart, Rome, Italy [Grant R4124500186 LINEA D.1 2014 and Grant R4124500458 LINEA D.1 2016].

\section{Conflict of Interest}

None.

\section{References}

1 Guarda G, So A. Regulation of inflammasome activity. Immunology 2010;130(03):329-336

2 Iwasaki A, Medzhitov R. Regulation of adaptive immunity by the innate immune system. Science 2010;327(5963):291-295

3 Eisenbarth SC, Flavell RA. Innate instruction of adaptive immunity revisited: the inflammasome. EMBO Mol Med 2009;1(02):92-98

4 Martinon F, Burns K, Tschopp J. The inflammasome: a molecular platform triggering activation of inflammatory caspases and processing of proIL-beta. Mol Cell 2002;10(02):417-426

5 Man SM, Kanneganti TD. Regulation of inflammasome activation. Immunol Rev 2015;265(01):6-21

6 Masters SL. Specific inflammasomes in complex diseases. Clin Immunol 2013;147(03):223-228 
7 Chen GY, Nuñez G. Sterile inflammation: sensing and reacting to damage. Nat Rev Immunol 2010;10(12):826-837

8 Jorgensen I, Rayamajhi M, Miao EA. Programmed cell death as a defence against infection. Nat Rev Immunol 2017;17(03): 151-164

9 Fink SL, Cookson BT. Caspase-1-dependent pore formation during pyroptosis leads to osmotic lysis of infected host macrophages. Cell Microbiol 2006;8(11):1812-1825

10 Liu X, Zhang Z, Ruan J, et al. Inflammasome-activated gasdermin D causes pyroptosis by forming membrane pores. Nature 2016; 535(7610):153-158

11 Kanneganti TD. Central roles of NLRs and inflammasomes in viral infection. Nat Rev Immunol 2010;10(10):688-698

12 Levinsohn JL, Newman ZL, Hellmich KA, et al. Anthrax lethal factor cleavage of Nlrp1 is required for activation of the inflammasome. PLoS Pathog 2012;8(03):e1002638

13 Shaw PJ, Lamkanfi M, Kanneganti TD. NOD-like receptor (NLR) signaling beyond the inflammasome. Eur J Immunol 2010;40 (03):624-627

14 Elinav E, Strowig T, Henao-Mejia J, Flavell RA. Regulation of the antimicrobial response by NLR proteins. Immunity 2011;34(05): 665-679

15 Mariathasan S, Newton K, Monack DM, et al. Differential activation of the inflammasome by caspase-1 adaptors ASC and Ipaf. Nature 2004;430(6996):213-218

16 Suzuki T, Franchi L, Toma C, et al. Differential regulation of caspase- 1 activation, pyroptosis, and autophagy via Ipaf and ASC in Shigella-infected macrophages. PLoS Pathog 2007;3(08): e111

17 Bauernfeind F, Hornung V. Of inflammasomes and pathogenssensing of microbes by the inflammasome. EMBO Mol Med 2013;5(06):814-826

18 Man SM, Kanneganti TD. Converging roles of caspases in inflammasome activation, cell death and innate immunity. Nat Rev Immunol 2016;16(01):7-21

19 Creagh EM. Caspase crosstalk: integration of apoptotic and innate immune signalling pathways. Trends Immunol 2014;35 (12):631-640

20 Strowig T, Henao-Mejia J, Elinav E, Flavell R. Inflammasomes in health and disease. Nature 2012;481(7381):278-286

21 Garlanda C, Dinarello CA, Mantovani A. The interleukin-1 family: back to the future. Immunity 2013;39(06):1003-1018

22 Dinarello CA. Immunological and inflammatory functions of the interleukin-1 family. Annu Rev Immunol 2009;27: 519-550

23 Bauernfeind FG, Horvath G, Stutz A, et al. Cutting edge: NFkappaB activating pattern recognition and cytokine receptors license NLRP3 inflammasome activation by regulating NLRP3 expression. J Immunol 2009;183(02):787-791

24 Elliott EI, Sutterwala FS. Initiation and perpetuation of NLRP3 inflammasome activation and assembly. Immunol Rev 2015;265 (01):35-52

25 Song N, Liu ZS, Xue W, et al. NLRP3 phosphorylation is an essential priming event for inflammasome activation. Mol Cell 2017;68(01):185-197.e6

26 He Y, Zeng MY, Yang D, Motro B, Núñez G. NEK7 is an essential mediator of NLRP3 activation downstream of potassium efflux. Nature 2016;530(7590):354-357

27 He Y, Hara H, Núñez G. Mechanism and regulation of NLRP3 inflammasome activation. Trends Biochem Sci 2016;41(12): 1012-1021

28 Folco EJ, Sukhova GK, Quillard T, Libby P. Moderate hypoxia potentiates interleukin- $1 \beta$ production in activated human macrophages. Circ Res 2014;115(10):875-883

29 Xiao H, Lu M, Lin TY, et al. Sterol regulatory element binding protein 2 activation of NLRP3 inflammasome in endothelium mediates hemodynamic-induced atherosclerosis susceptibility. Circulation 2013;128(06):632-642
30 Li X, Thome S, Ma X, et al. MARK4 regulates NLRP3 positioning and inflammasome activation through a microtubule-dependent mechanism. Nat Commun 2017;8:15986

31 Wright SD, Burton C, Hernandez M, et al. Infectious agents are not necessary for murine atherogenesis. J Exp Med 2000;191 (08):1437-1442

32 Piccinini AM, Midwood KS. DAMPening inflammation by modulating TLR signalling. Mediators Inflamm 2010;2010:pii: 672395. Doi: 10.1155/2010/672395

33 Duewell P, Kono H, Rayner KJ, et al. NLRP3 inflammasomes are required for atherogenesis and activated by cholesterol crystals. Nature 2010;464(7293):1357-1361

34 Waehre T, Yndestad A, Smith C, et al. Increased expression of interleukin-1 in coronary artery disease with downregulatory effects of HMG-CoA reductase inhibitors. Circulation 2004;109 (16):1966-1972

35 Mallat Z, Henry P, Fressonnet R, et al. Increased plasma concentrations of interleukin-18 in acute coronary syndromes. Heart 2002;88(05):467-469

36 Shimpo M, Morrow DA, Weinberg EO, et al. Serum levels of the interleukin-1 receptor family member ST2 predict mortality and clinical outcome in acute myocardial infarction. Circulation 2004;109(18):2186-2190

37 Blankenberg S, McQueen MJ, Smieja M, et al; HOPE Study Investigators. Comparative impact of multiple biomarkers and $\mathrm{N}$-Terminal pro-brain natriuretic peptide in the context of conventional risk factors for the prediction of recurrent cardiovascular events in the Heart Outcomes Prevention Evaluation (HOPE) Study. Circulation 2006;114(03):201-208

38 Tedgui A, Mallat Z. Cytokines in atherosclerosis: pathogenic and regulatory pathways. Physiol Rev 2006;86(02):515-581

39 Afrasyab A, Qu P, Zhao Y, et al. Correlation of NLRP3 with severity and prognosis of coronary atherosclerosis in acute coronary syndrome patients. Heart Vessels 2016;31(08): 1218-1229

40 Olofsson PS, Sheikine Y, Jatta K, et al. A functional interleukin-1 receptor antagonist polymorphism influences atherosclerosis development. The interleukin-1beta:interleukin-1 receptor antagonist balance in atherosclerosis. Circ J 2009;73(08):1531-1536

41 Persson J, Nilsson J, Lindholm MW. Interleukin-1beta and tumour necrosis factor-alpha impede neutral lipid turnover in macrophage-derived foam cells. BMC Immunol 2008; 9:70

42 Rajamäki K, Lappalainen J, Oörni K, et al. Cholesterol crystals activate the NLRP3 inflammasome in human macrophages: a novel link between cholesterol metabolism and inflammation. PLoS One 2010;5(07):e11765

43 Liu W, Yin Y, Zhou Z, He M, Dai Y. OxLDL-induced IL-1 beta secretion promoting foam cells formation was mainly via CD36 mediated ROS production leading to NLRP3 inflammasome activation. Inflamm Res 2014;63(01):33-43

44 Sheedy FJ, Grebe A, Rayner KJ, et al. CD36 coordinates NLRP3 inflammasome activation by facilitating intracellular nucleation of soluble ligands into particulate ligands in sterile inflammation. Nat Immunol 2013;14(08):812-820

45 Stachon P, Heidenreich A, Merz J, et al. P2X ${ }_{7}$ deficiency blocks lesional inflammasome activity and ameliorates atherosclerosis in mice. Circulation 2017;135(25):2524-2533

46 Samstad EO, Niyonzima N, Nymo S, et al. Cholesterol crystals induce complement-dependent inflammasome activation and cytokine release. J Immunol 2014;192(06):2837-2845

47 Triantafilou M, Hughes TR, Morgan BP, Triantafilou K. Complementing the inflammasome. Immunology 2016;147(02): $152-164$

48 Triantafilou K, Hughes TR, Triantafilou M, Morgan BP. The complement membrane attack complex triggers intracellular $\mathrm{Ca} 2+$ fluxes leading to NLRP3 inflammasome activation.J Cell Sci 2013;126(Pt 13):2903-2913 
49 Benoit ME, Clarke EV, Morgado P, Fraser DA, Tenner AJ. Complement protein $\mathrm{C} 1 \mathrm{q}$ directs macrophage polarization and limits inflammasome activity during the uptake of apoptotic cells. J Immunol 2012;188(11):5682-5693

50 Pedicino D, Giglio AF, Galiffa VA, et al. Infections, immunity and atherosclerosis: pathogenic mechanisms and unsolved questions. Int J Cardiol 2013;166(03):572-583

51 Alexander MR, Moehle CW, Johnson JL, et al. Genetic inactivation of IL-1 signaling enhances atherosclerotic plaque instability and reduces outward vessel remodeling in advanced atherosclerosis in mice. J Clin Invest 2012;122(01):70-79

52 Menu P, Pellegrin M, Aubert JF, et al. Atherosclerosis in ApoEdeficient mice progresses independently of the NLRP3 inflammasome. Cell Death Dis 2011;2:e137

53 Baldrighi M, Mallat Z, Li X. NLRP3 inflammasome pathways in atherosclerosis. Atherosclerosis 2017;267:127-138

54 Mallat Z, Corbaz A, Scoazec A, et al. Expression of interleukin-18 in human atherosclerotic plaques and relation to plaque instability. Circulation 2001;104(14):1598-1603

55 Mallat Z, Corbaz A, Scoazec A, et al. Interleukin-18/interleukin18 binding protein signaling modulates atherosclerotic lesion development and stability. Circ Res 2001;89(07):E41-E45

56 Elhage R, Jawien J, Rudling M, et al. Reduced atherosclerosis in interleukin-18 deficient apolipoprotein E-knockout mice. Cardiovasc Res 2003;59(01):234-240

57 Zirlik A, Abdullah SM, Gerdes N, et al. Interleukin-18, the metabolic syndrome, and subclinical atherosclerosis: results from the Dallas Heart Study. Arterioscler Thromb Vasc Biol 2007;27(09):2043-2049

58 Janoudi A, Shamoun FE, Kalavakunta JK, Abela GS. Cholesterol crystal induced arterial inflammation and destabilization of atherosclerotic plaque. Eur Heart J 2016;37(25):1959-1967

59 Niccoli G, Liuzzo G, Montone RA, Crea F. Advances in mechanisms, imaging and management of the unstable plaque. Atherosclerosis 2014;233(02):467-477

60 Liuzzo G, Giubilato G, Pinnelli M. T cells and cytokines in atherogenesis. Lupus 2005;14(09):732-735

61 Liuzzo G, Biasucci LM, Gallimore JR, et al. The prognostic value of C-reactive protein and serum amyloid a protein in severe unstable angina. N Engl J Med 1994;331(07):417-424

62 Abbate A, Biondi-Zoccai GG, Brugaletta S, Liuzzo G, Biasucci LM. C-reactive protein and other inflammatory biomarkers as predictors of outcome following acute coronary syndromes. Semin Vasc Med 2003;3(04):375-384

63 Pedicino D, Severino A, Ucci S, et al. Epicardial adipose tissue microbial colonization and inflammasome activation in acute coronary syndrome. Int J Cardiol 2017;236:95-99

64 Toldo S, Mezzaroma E, Mauro AG, Salloum F, Van Tassell BW, Abbate A. The inflammasome in myocardial injury and cardiac remodeling. Antioxid Redox Signal 2015;22(13):1146-1161

65 Frantz S, Ducharme A, Sawyer D, et al. Targeted deletion of caspase- 1 reduces early mortality and left ventricular dilatation following myocardial infarction. J Mol Cell Cardiol 2003;35(06): 685-694

66 Venkatachalam K, Prabhu SD, Reddy VS, Boylston WH, Valente AJ, Chandrasekar B. Neutralization of interleukin-18 ameliorates ischemia/reperfusion-induced myocardial injury. J Biol Chem 2009;284(12):7853-7865

67 Buffon A, Biasucci LM, Liuzzo G, D’Onofrio G, Crea F, Maseri A. Widespread coronary inflammation in unstable angina. $\mathrm{N}$ Engl J Med 2002;347(01):5-12

68 Narducci ML, Grasselli A, Biasucci LM, et al. High telomerase activity in neutrophils from unstable coronary plaques. J Am Coll Cardiol 2007;50(25):2369-2374

69 Biasucci LM, Liuzzo G, Giubilato S, et al. Delayed neutrophil apoptosis in patients with unstable angina: relation to C-reactive protein and recurrence of instability. Eur Heart J 2009;30(18): $2220-2225$
70 Ferrante G, Nakano M, Prati F, et al. High levels of systemic myeloperoxidase are associated with coronary plaque erosion in patients with acute coronary syndromes: a clinicopathological study. Circulation 2010;122(24):2505-2513

71 Franck G, Mawson T, Sausen G, et al. Flow perturbation mediates neutrophil recruitment and potentiates endothelial injury via TLR2 in mice: implications for superficial erosion. Circ Res 2017; 121(01):31-42

72 Libby P, Nahrendorf M, Pittet MJ, Swirski FK. Diversity of denizens of the atherosclerotic plaque: not all monocytes are created equal. Circulation 2008;117(25):3168-3170

73 Hilgendorf I, Swirski FK, Robbins CS. Monocyte fate in atherosclerosis. Arterioscler Thromb Vasc Biol 2015;35(02):272-279

74 Tsujioka H, Imanishi T, Ikejima H, et al. Impact of heterogeneity of human peripheral blood monocyte subsets on myocardial salvage in patients with primary acute myocardial infarction. J Am Coll Cardiol 2009;54(02):130-138

75 Wyss CA, Neidhart M, Altwegg L, et al. Cellular actors, Toll-like receptors, and local cytokine profile in acute coronary syndromes. Eur Heart J 2010;31(12):1457-1469

76 Niessner A, Shin MS, Pryshchep O, Goronzy JJ, Chaikof EL, Weyand CM. Synergistic proinflammatory effects of the antiviral cytokine interferon-alpha and Toll-like receptor 4 ligands in the atherosclerotic plaque. Circulation 2007;116(18): 2043-2052

77 Souders CA, Bowers SL, Baudino TA. Cardiac fibroblast: the renaissance cell. Circ Res 2009;105(12):1164-1176

78 Sandanger $\emptyset$, Ranheim T, Vinge LE, et al. The NLRP3 inflammasome is up-regulated in cardiac fibroblasts and mediates myocardial ischaemia-reperfusion injury. Cardiovasc Res 2013;99 (01):164-174

79 Marchant DJ, Boyd JH, Lin DC, Granville DJ, Garmaroudi FS, McManus BM. Inflammation in myocardial diseases. Circ Res 2012;110(01):126-144

80 Pomerantz BJ, Reznikov LL, Harken AH, Dinarello CA. Inhibition of caspase 1 reduces human myocardial ischemic dysfunction via inhibition of IL-18 and IL-1 beta. Proc Natl Acad Sci U S A 2001;98 (05):2871-2876

81 Mallat Z, Heymes C, Corbaz A, et al. Evidence for altered interleukin 18 (IL)-18 pathway in human heart failure. FASEB J 2004; 18(14):1752-1754

82 Kawaguchi M, Takahashi M, Hata T, et al. Inflammasome activation of cardiac fibroblasts is essential for myocardial ischemia/ reperfusion injury. Circulation 2011;123(06):594-604

83 Marchetti C, Chojnacki J, Toldo S, et al. A novel pharmacologic inhibitor of the NLRP3 inflammasome limits myocardial injury after ischemia-reperfusion in the mouse. J Cardiovasc Pharmacol 2014;63(04):316-322

84 Ding Z, Liu S, Wang X, et al. LOX-1, mtDNA damage, and NLRP3 inflammasome activation in macrophages: implications in atherogenesis. Cardiovasc Res 2014;103(04):619-628

85 Liu SJ, Zhou W, Kennedy RH. Suppression of beta-adrenergic responsiveness of L-type Ca2 + current by IL-1beta in rat ventricular myocytes. Am J Physiol 1999;276(1 Pt 2):H141-H148

86 Chung MK, Gulick TS, Rotondo RE, Schreiner GF, Lange LG. Mechanism of cytokine inhibition of beta-adrenergic agonist stimulation of cyclic AMP in rat cardiac myocytes. Impairment of signal transduction. Circ Res 1990;67(03):753-763

87 McTiernan CF, Lemster BH, Frye C, Brooks S, Combes A, Feldman AM. Interleukin-1 beta inhibits phospholamban gene expression in cultured cardiomyocytes. Circ Res 1997;81(04):493-503

88 Tsujino M, Hirata $Y$, Imai $T$, et al. Induction of nitric oxide synthase gene by interleukin-1 beta in cultured rat cardiocytes. Circulation 1994;90(01):375-383

89 van Hout GP, Bosch L, Ellenbroek GH, et al. The selective NLRP3inflammasome inhibitor MCC950 reduces infarct size and preserves cardiac function in a pig model of myocardial infarction. Eur Heart J 2017;38(11):828-836 
90 Cayrol C, Girard JP. The IL-1-like cytokine IL-33 is inactivated after maturation by caspase-1. Proc Natl Acad Sci U S A 2009;106 (22):9021-9026

91 Seki K, Sanada S, Kudinova AY, et al. Interleukin-33 prevents apoptosis and improves survival after experimental myocardial infarction through ST2 signaling. Circ Heart Fail 2009;2(06): 684-691

92 Jonasson L, Holm J, Skalli O, Gabbiani G, Hansson GK. Expression of class II transplantation antigen on vascular smooth muscle cells in human atherosclerosis. J Clin Invest 1985;76(01):125-131

93 Ketelhuth DF, Hansson GK. Cellular immunity, low-density lipoprotein and atherosclerosis: break of tolerance in the artery wall. Thromb Haemost 2011;106(05):779-786

94 Flego D, Liuzzo G, Weyand CM, Crea F. Adaptive immunity dysregulation in acute coronary syndromes: from cellular and molecular basis to clinical implications. J Am Coll Cardiol 2016; 68(19):2107-2117

95 Liuzzo G, Biasucci LM, Trotta G, et al. Unusual CD4+CD28null T lymphocytes and recurrence of acute coronary events. J Am Coll Cardiol 2007;50(15):1450-1458

96 Liuzzo G, Montone RA, Gabriele M, et al. Identification of unique adaptive immune system signature in acute coronary syndromes. Int J Cardiol 2013;168(01):564-567

97 Zhou X, Robertson AK, Rudling M, Parini P, Hansson GK. Lesion development and response to immunization reveal a complex role for CD4 in atherosclerosis. Circ Res 2005;96(04):427-434

98 Buono C, Binder CJ, Stavrakis G, Witztum JL, Glimcher LH, Lichtman AH. T-bet deficiency reduces atherosclerosis and alters plaque antigen-specific immune responses. Proc Natl Acad Sci U S A 2005;102(05):1596-1601

99 Buono C, Come CE, Stavrakis G, Maguire GF, Connelly PW, Lichtman AH. Influence of interferon-gamma on the extent and phenotype of diet-induced atherosclerosis in the LDLRdeficient mouse. Arterioscler Thromb Vasc Biol 2003;23(03): 454-460

100 King VL, Szilvassy SJ, Daugherty A. Interleukin-4 deficiency decreases atherosclerotic lesion formation in a site-specific manner in female LDL receptor-/- mice. Arterioscler Thromb Vasc Biol 2002;22(03):456-461

101 Binder CJ, Hartvigsen K, Chang MK, et al. IL-5 links adaptive and natural immunity specific for epitopes of oxidized LDL and protects from atherosclerosis. J Clin Invest 2004;114(03):427-437

102 de Boer OJ, van der Meer JJ, Teeling P, van der Loos CM, van der Wal AC. Low numbers of FOXP3 positive regulatory $\mathrm{T}$ cells are present in all developmental stages of human atherosclerotic lesions. PLoS One 2007;2(08):e779

103 Xiong Z, Song J, Yan Y, et al. Higher expression of Bax in regulatory $T$ cells increases vascular inflammation. Front Biosci 2008;13:7143-7155

104 Ait-Oufella H, Salomon BL, Potteaux S, et al. Natural regulatory T cells control the development of atherosclerosis in mice. Nat Med 2006;12(02):178-180

105 Mor A, Planer D, Luboshits G, et al. Role of naturally occurring CD4+ CD25+ regulatory T cells in experimental atherosclerosis. Arterioscler Thromb Vasc Biol 2007;27(04):893-900

106 Mallat Z, Gojova A, Brun V, et al. Induction of a regulatory T cell type 1 response reduces the development of atherosclerosis in apolipoprotein E-knockout mice. Circulation 2003;108(10): $1232-1237$

107 Mallat Z, Besnard S, Duriez M, et al. Protective role of interleukin10 in atherosclerosis. Circ Res 1999;85(08):e17-e24

108 Robertson AK, Rudling M, Zhou X, Gorelik L, Flavell RA, Hansson GK. Disruption of TGF-beta signaling in $T$ cells accelerates atherosclerosis. J Clin Invest 2003;112(09):1342-1350

109 Liu Z, Lu F, Pan H, et al. Correlation of peripheral Th17 cells and Th17-associated cytokines to the severity of carotid artery plaque and its clinical implication. Atherosclerosis 2012;221 (01):232-241
110 Erbel C, Dengler TJ, Wangler S, et al. Expression of IL-17A in human atherosclerotic lesions is associated with increased inflammation and plaque vulnerability. Basic Res Cardiol 2011;106(01):125-134

111 Cheng X, Yu X, Ding YJ, et al. The Th17/Treg imbalance in patients with acute coronary syndrome. Clin Immunol 2008;127(01): 89-97

112 Zhao Z, Wu Y, Cheng M, et al. Activation of Th17/Th1 and Th1, but not Th17, is associated with the acute cardiac event in patients with acute coronary syndrome. Atherosclerosis 2011;217(02): 518-524

113 Li Q, Wang Y, Chen K, et al. The role of oxidized low-density lipoprotein in breaking peripheral Th17/Treg balance in patients with acute coronary syndrome. Biochem Biophys Res Commun 2010;394(03):836-842

114 Taleb S, Romain M, Ramkhelawon B, et al. Loss of SOCS3 expression in $\mathrm{T}$ cells reveals a regulatory role for interleukin17 in atherosclerosis. J Exp Med 2009;206(10):2067-2077

115 Brauner S, Jiang X, Thorlacius GE, et al. Augmented Th17 differentiation in Trim21 deficiency promotes a stable phenotype of atherosclerotic plaques with high collagen content. Cardiovasc Res 2018;114(01):158-167

116 Simon T, Taleb S, Danchin N, et al. Circulating levels of interleukin-17 and cardiovascular outcomes in patients with acute myocardial infarction. Eur Heart J 2013;34(08):570-577

117 Liuzzo G, Trotta F, Pedicino D. Interleukin-17 in atherosclerosis and cardiovascular disease: the good, the bad, and the unknown. Eur Heart J 2013;34(08):556-559

118 Giubilato S, Liuzzo G, Brugaletta S, et al. Expansion of CD4+CD28null T-lymphocytes in diabetic patients: exploring new pathogenetic mechanisms of increased cardiovascular risk in diabetes mellitus. Eur Heart J 2011;32(10): 1214-1226

119 Flego D, Severino A, Trotta F, et al. Altered CD31 expression and activity in helper $\mathrm{T}$ cells of acute coronary syndrome patients. Basic Res Cardiol 2014;109(06):448

120 Flego D, Severino A, Trotta F, et al. Increased PTPN22 expression and defective CREB activation impair regulatory T-cell differentiation in non-ST-segment elevation acute coronary syndromes. J Am Coll Cardiol 2015;65(12):1175-1186

121 Sutterwala FS, Ogura Y, Szczepanik M, et al. Critical role for NALP3/CIAS1/Cryopyrin in innate and adaptive immunity through its regulation of caspase-1. Immunity 2006;24(03): 317-327

122 Ghiringhelli F, Apetoh L, Tesniere A, et al. Activation of the NLRP3 inflammasome in dendritic cells induces IL-1beta-dependent adaptive immunity against tumors. Nat Med 2009;15(10): 1170-1178

123 Jin Y, Mailloux CM, Gowan K, et al. NALP1 in vitiligo-associated multiple autoimmune disease. N Engl J Med 2007;356(12): 1216-1225

124 Brydges SD, Mueller JL, McGeough MD, et al. Inflammasomemediated disease animal models reveal roles for innate but not adaptive immunity. Immunity 2009;30(06):875-887

125 Meng G, Zhang F, Fuss I, Kitani A, Strober W. A mutation in the Nlrp3 gene causing inflammasome hyperactivation potentiates Th17 cell-dominant immune responses. Immunity 2009;30(06): 860-874

126 Arbore G, West EE, Spolski R, et al. T helper 1 immunity requires complement-driven NLRP3 inflammasome activity in $\mathrm{CD}^{+} \mathrm{T}$ cells. Science 2016;352(6292):aad1210

127 Zielinski CE, Mele F, Aschenbrenner D, et al. Pathogen-induced human TH17 cells produce IFN-r or IL-10 and are regulated by IL1ß. Nature 2012;484(7395):514-518

128 Sutton C, Brereton C, Keogh B, Mills KH, Lavelle EC. A crucial role for interleukin (IL)-1 in the induction of IL-17-producing T cells that mediate autoimmune encephalomyelitis. J Exp Med 2006; 203(07):1685-1691 
129 Cho ML, Kang JW, Moon YM, et al. STAT3 and NF-kappaB signal pathway is required for IL-23-mediated IL-17 production in spontaneous arthritis animal model IL-1 receptor antagonistdeficient mice. J Immunol 2006;176(09):5652-5661

130 Nakae S, Saijo S, Horai R, Sudo K, Mori S, Iwakura Y. IL-17 production from activated $T$ cells is required for the spontaneous development of destructive arthritis in mice deficient in IL-1 receptor antagonist. Proc Natl Acad Sci U S A 2003;100(10): 5986-5990

131 Inoue M, Williams KL, Gunn MD, Shinohara ML. NLRP3 inflammasome induces chemotactic immune cell migration to the CNS in experimental autoimmune encephalomyelitis. Proc Natl Acad Sci U S A 2012;109(26):10480-10485

132 Koenders MI, Devesa I, Marijnissen RJ, et al. Interleukin-1 drives pathogenic Th17 cells during spontaneous arthritis in interleukin-1 receptor antagonist-deficient mice. Arthritis Rheum 2008; 58(11):3461-3470

133 Mercer F, Kozhaya L, Unutmaz D. Expression and function of TNF and IL-1 receptors on human regulatory T cells. PLoS One 2010;5 (01):e8639

134 Dinarello CA. IL-18: A TH1-inducing, proinflammatory cytokine and new member of the IL-1 family. J Allergy Clin Immunol 1999; 103(1 Pt 1):11-24

135 Beaulieu LM, Lin E, Mick E, et al. Interleukin 1 receptor 1 and interleukin $1 \beta$ regulate megakaryocyte maturation, platelet activation, and transcript profile during inflammation in mice and humans. Arterioscler Thromb Vasc Biol 2014;34(03): 552-564

136 Shao BZ, Xu ZQ, Han BZ, Su DF, Liu C. NLRP3 inflammasome and its inhibitors: a review. Front Pharmacol 2015;6:262

137 Bona RD, Liuzzo G, Pedicino D, Crea F. Anti-inflammatory treatment of acute coronary syndromes. Curr Pharm Des 2011;17 (37):4172-4189

138 Crea F, Liuzzo G. Anti-inflammatory treatment of acute coronary syndromes: the need for precision medicine. Eur Heart J 2016;37 (30):2414-2416

139 Morton AC, Rothman AM, Greenwood JP, et al. The effect of interleukin-1 receptor antagonist therapy on markers of inflammation in non-ST elevation acute coronary syndromes: the MRCILA Heart Study. Eur Heart J 2015;36(06):377-384

140 Abbate A, Kontos MC, Grizzard JD, et al; VCU-ART Investigators. Interleukin-1 blockade with anakinra to prevent adverse cardiac remodeling after acute myocardial infarction (Virginia Common- wealth University Anakinra Remodeling Trial [VCU-ART] Pilot study). Am J Cardiol 2010;105(10):1371-1377.e1

141 Abbate A, Van Tassell BW, Biondi-Zoccai G, et al. Effects of interleukin-1 blockade with anakinra on adverse cardiac remodeling and heart failure after acute myocardial infarction [from the Virginia Commonwealth University-Anakinra Remodeling Trial (2) (VCU-ART2) pilot study]. Am J Cardiol 2013;111(10): 1394-1400

142 Abbate A, Salloum FN, Vecile E, et al. Anakinra, a recombinant human interleukin-1 receptor antagonist, inhibits apoptosis in experimental acute myocardial infarction. Circulation 2008;117 (20):2670-2683

143 Available at: http://clinicaltrials.gov; (NCT01950299) Interleukin- 1 (IL-1) Blockade in Acute Myocardial Infarction (VCUART3). Accessed June 20, 2018

144 Ikonomidis I, Lekakis JP, Nikolaou M, et al. Inhibition of interleukin-1 by anakinra improves vascular and left ventricular function in patients with rheumatoid arthritis. Circulation 2008;117(20):2662-2669

145 Van Tassell BW, Arena RA, Toldo S, et al. Enhanced interleukin-1 activity contributes to exercise intolerance in patients with systolic heart failure. PLoS One 2012;7(03):e33438

146 Van Tassell BW, Arena R, Biondi-Zoccai G, et al. Effects of interleukin-1 blockade with anakinra on aerobic exercise capacity in patients with heart failure and preserved ejection fraction (from the D-HART pilot study). Am J Cardiol 2014;113(02): 321-327

147 Van Tassell BW, Canada J, Carbone S, et al. Interleukin-1 Blockade in Recently Decompensated Systolic Heart Failure: Results From REDHART (Recently Decompensated Heart Failure Anakinra Response Trial). Circ Heart Fail 2017;10(11):pii: e004373

148 Available at: http://clinicaltrials.gov (NCT02173548). Accessed June 20, 2018

149 Ridker PM, Everett BM, Thuren T, et al; CANTOS Trial Group. Antiinflammatory therapy with canakinumab for atherosclerotic disease. N Engl J Med 2017;377(12):1119-1131

150 Ridker PM, MacFadyen JG, Everett BM, Libby P, Thuren T, Glynn RJ; CANTOS Trial Group. Relationship of C-reactive protein reduction to cardiovascular event reduction following treatment with canakinumab: a secondary analysis from the CANTOS randomised controlled trial. Lancet 2018;391(10118):319-328

151 Harrington RA. Targeting inflammation in coronary artery disease. N Engl J Med 2017;377(12):1197-1198 